OPEN ACCESS

Edited by: Benjamin Frey,

University Hospital Erlangen, Germany

Reviewed by:

Ji Dan,

Central South University, China

Xin Huang,

Renmin Hospital of Wuhan University,

China

${ }^{*}$ Correspondence:

Xin Wei

weixin_1982@163.com

Specialty section: This article was submitted to

Cancer Immunity and

Immunotherapy,

a section of the journal

Frontiers in Immunology

Received: 28 April 2021 Accepted: 05 August 2021 Published: 24 August 2021

Citation:

Zhou L and Wei X (2021) Ocular Immune-Related Adverse Events Associated With Immune Checkpoint Inhibitors in Lung Cancer.

Front. Immunol. 12:701951. doi: 10.3389/fimmu.2021.701951

\section{Ocular Immune-Related Adverse Events Associated With Immune Checkpoint Inhibitors in Lung Cancer}

\author{
Lin Zhou and Xin Wei* \\ Department of Ophthalmology, West China Hospital, Sichuan University, Chengdu, China
}

Immune checkpoint inhibitors (ICls) are novel immunotherapy-based drugs that have become increasingly popular in the treatment of lung cancer. Researchers have recognized ocular immune-related adverse events (irAEs) secondary to ICls because of their vision-threatening characteristics. However, they are incompletely characterized and no studies have reported the ICl-related ocular irAEs in lung cancer. Therefore, we aimed to comprehensively illustrate the clinical characteristics, contributory factors, diagnosis, and management of ICl-related ocular irAEs in lung cancer, based on previously reported 79 patients. Ophthalmoplegia (40.51\%), uveitis (20.25\%), and dry eye (17.72\%) were the most common ICl-related ocular irAEs in lung cancer. Ptosis was the most common (36.71\%) and the highest mortality (23.33\%) of ophthalmoplegia. Patients in Asia and patients who underwent combination therapy with programmed cell death-1 and cytotoxic T-lymphocyte-associated antigen 4 inhibitors demonstrated significantly higher frequency of ophthalmoplegia than other ocular irAEs. Most ICl-related ophthalmoplegia and uveitis in lung cancer were observed in the first 10 weeks following the initiation of ICls. Furthermore, the onset time of dry eye and other ocular irAEs was much longer. In addition, 92.31\% of the patients with ocular irAEs other than ophthalmoplegia could be remised. In conclusion, ocular irAEs secondary to ICls in lung cancer are non-negligible, particularly ophthalmoplegia. Ethnicity and the type of ICls play important roles in the distribution of ocular irAEs. ICl-related ophthalmoplegia in lung cancer presented with early onset and worse prognosis features, thus necessitating further attention.

\section{Keywords: ocular immune-related adverse events, immune checkpoint inhibitors, lung cancer, ophthalmoplegia,} uveitis, dry eye

\section{INTRODUCTION}

Lung cancer is diagnosed in approximately two million people (11.6\% of the total cancer cases), and is a leading cause of cancer death worldwide (1-3). Based on the histologic subtypes, lung cancer has been classified as large cell carcinoma, squamous carcinoma, and adenocarcinoma (NSCLC, nonsmall cell carcinoma), and small cell lung cancer. With the identification of molecular mechanisms by which cancerous cells evade $\mathrm{T}$ cell-mediated cytotoxic damage, immunotherapy has been considered as an effective treatment for patients with lung cancer (4-6). 
Immune system plays an important role in monitoring and destructing cancer cells. However, this natural defense can be evaded by tumor cells and the upregulation of key immune checkpoints could increase the tolerance. Antitumor immunity may be blocked by suppression through the activation of immune checkpoints, including the cytotoxic T-lymphocyteassociated antigen 4 (CTLA-4) and programmed cell death-1 protein (PD-1) pathways. Blocking the inhibitory molecular axis using monoclonal antibodies targeting PD-1 (nivolumab, pembrolizumab), PD-L1 (atezolizumab, avelumab, and durvalumab), or CTLA-4 (ipilimumab) can reactivate the effector and cytotoxic T cells to destroy the tumor cells $(7,8)$. Immune checkpoint inhibitors (ICIs) provide a long-lasting response to treatment in both at the early and late stage of lung cancer (9-11). It has been considered as the first choice of second-line therapy for advanced NSCLC and as first-line therapy $(4,12,13)$.

Compared to the traditional therapy, ICIs can over-activate the non-specific the immune system, which could cause autoimmune toxicities known as immune-related adverse events (irAEs) (14-18). This in turn can affect any organ system, including the skin, heart, lungs, liver, kidneys, central nervous, gastrointestinal, endocrine, musculoskeletal, haematological, and ocular systems. The most common systemic irAEs include fatigue (26\%-53\%), skin pruritus $(25 \%-$ $35 \%)$, skin rash $(1 \%-50 \%)$, lymphocytopenia $(10 \%-49 \%)$, and abnormal liver function (1\%-46\%) (19). Following ICIs, the aforementioned irAEs may manifest as a wide variety of forms ranging from mild to severe (20), and vary based on the organ system and severity $(21,22)$. The prevalence of ICI-related pneumonitis is higher in NSCLC than in other tumor type, based on data from the Immuno-Cancer International Registry $(23,24)$. In addition, lung cancer is reportedly one of the most common tumor with ICI-related ocular irAEs (25).

Ocular irAEs following ICIs can cause a deterioration of the quality of life and exert an influence on the compliance of patients. Approximately $2.8-4.3 \%$ of the patients suffered ocular irAEs, based on the Food and Drug Administration (FDA) Adverse Event Reporting System pharmacovigilance database (26-28). However, no studies have comprehensively analyzed ocular irAEs in lung cancer following ICIs. We aim to evaluate uncommon and serious ICI-related ocular irAEs associated with lung cancer. Based on relevant literature on ocular irAEs in lung cancer, we intent to illustrate the epidemiology, clinical characteristics, contributory factors, diagnosis, and management of ICI-associated ocular side effects in lung cancer.

\section{EPIDEMIOLOGY OF OCULAR IrAES IN LUNG CANCER}

Despite being infrequent, ocular irAEs can cause a deterioration of the quality of life and affect patient compliance. Initially, the incidence of ICI-related ocular irAEs was estimated to be approximately $0.4 \%-1 \%$ in patients with moderate-to-severe ocular irAEs $(19,29)$. Recently, three studies with large sample sizes have reported an incidence of $2.8-4.3 \%(26,30,31)$. In addition, the actual frequency of ocular irAEs following ICIs could be underestimated because of insufficient attention. The incidence of ICI-associated ocular complications may be higher in real-world practice.

Ocular side effects secondary to ICIs are immune-related, and can affect any part of the eye and orbit. The distribution and frequency vary in different ocular irAEs on ICIs. In 2018, uveitis and dry eye had been reported as the most frequent ICI-related ocular side effects. Ocular irAEs were reported in $2.80 \%$ patients in a cohort of 996 patients with ICIs reported in Mayo clinic (31). Dry eye was observed in $57.14 \%$ of the patients with ocular irAEs, followed by uveitis in $14.28 \%$ of the patients (31). In relation to ICI-associated ocular surface toxicity, dry eye, conjunctivitis, and keratitis were reportedly the most common irAEs in a previous review involving 29 studies (32). However, a systematic review on ipilimumab considered uveitis $(4.3 \%)$ as the most common ocular $\operatorname{irAE}(27,28)$. Anterior uveitis is the most common phenotype among all types of uveitis (30). Despite some reports on ophthalmoplegia, it is not considered as a common side effect (19).

In this review, we summarized the reported ocular irAEs following ICIs in lung cancer by searching the PubMed database until April 2021 (25, 29, 33-86). The key words were a combination of 'adverse events', 'lung', and names of ICIs. We included studies describing ocular irAEs secondary to ICIs in lung cancer, and restricted the language of the selected literature to English. A total of 79 cases were detected, and the most frequently reported ocular irAEs following ICIs were ophthalmoplegia (40.51\%), uveitis $(20.25 \%)$, and dry eye (17.72\%). In addition, we also identified retinopathy $(5.06 \%)$, conjunctivitis (5.06\%), optic neuritis (3.80\%), and other frequent ocular irAEs, such as orbital inflammation (2.53\%), amaurosis fugax $(1.27 \%)$, giant cell arteritis $(1.27 \%)$, corneal graft rejection (1.27\%) and corneal perforation (1.27\%) (Figure 1, Tables 1, 2).

\section{CLINICAL CHARACTERISTIC OF OCULAR irAEs IN LUNG CANCER WITH ICIS}

\section{The Onset Time of Ocular irAEs in Lung Cancer}

The mean time to the onset of ocular irAEs in lung cancer was approximately 35 days, and the overall time ranged from 28.0111.5 days $(19,87)$. Moreover, $73 \%$ of the patients developed ocular irAEs within 60 days following ICIs initiation. While intraocular inflammation was detected after a median 9 weeks, $83.6 \%-91.67 \%$ of the patients were diagnosed with uveitis within 6 months (median 63 days) $(28,88)$. Ophthalmoplegia was diagnosed at a median onset of 35 days. According to recent reviews on ocular adverse events, the average onset time of ophthalmoplegia was approximately 6 weeks after ICIs initiation (range 2-12 weeks) (19, 89-91). The median interval between the onset of ICIs use and the diagnosis of dry eye was 6.5 months in 26 patients secondary to ICIs (24). In this review, the 

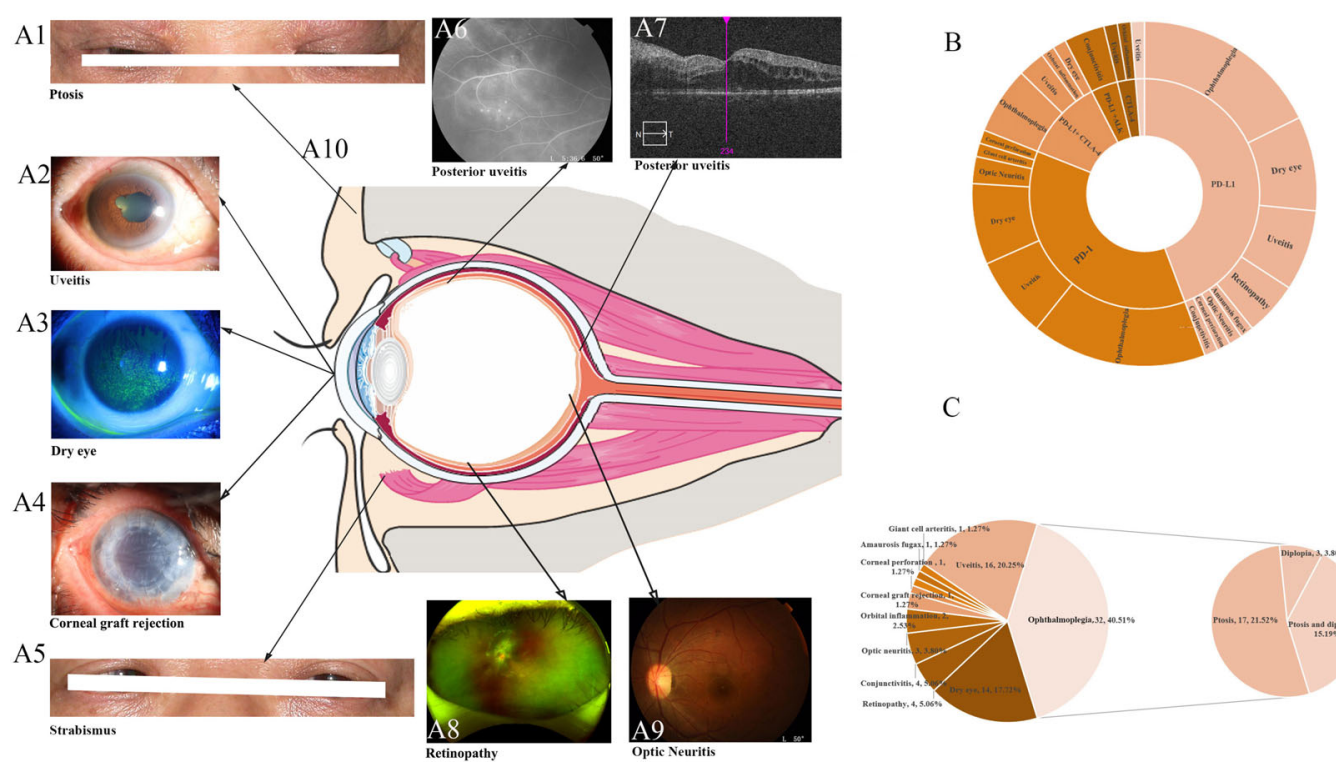

C

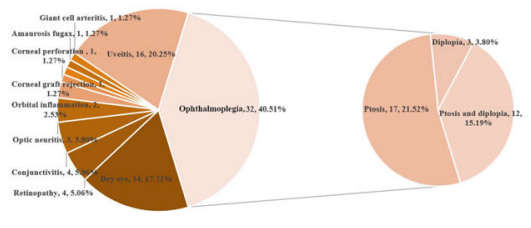

FIGURE 1 | Clinical characteristics (A) and the distribution (B, C) of immune checkpoint inhibitor-mediated ocular side events. (A) The clinical characteristics of common ocular irAEs in lung cancer. (B) The distribution of ocular irAEs in different therapies. (C) A summary of all reported ocular irAEs in lung cancer following treatment with ICls.

average onset time of ocular irAEs in lung cancer was 57.28 days following ICIs (Tables 1, 2, Figures 2, 3). The average time was significantly shorter in patients with uveitis and ophthalmoplegia (32.22 days and 38.26 days, respectively) than those with other ocular irAEs (96.5 days) in lung cancer. More importantly, all ICI-related ophthalmoplegia and the majority of uveitis occurred in the first 10 weeks. However, the onset time of dry eye and other ocular irAEs was much longer (Figures 2, 3). Furthermore, we did not detect a significant difference in the onset time of ocular irAEs in lung cancer among different ICIs, age, sex, and ethnicity (Figure S1).

\section{The Clinical Manifestation of Ocular irAEs in Lung Cancer}

All of the ocular irAEs following ICIs were noninfectious and caused by the over-activate the immune system. Table 3 summarizes the clinical characteristics and necessary examinations for different ocular irAEs. Ophthalmoplegia, uveitis and dry eye were the most common ocular irAEs secondary to ICIs in lung cancer have been described separately in detail as follows. Other ocular surface complications (conjunctivitis, corneal perforation, corneal graft rejection, retinopathy, optic neuritis, amaurosis fugax, giant cell arteritis and orbital inflammation) are also briefly discussed.

\section{Ophthalmoplegia in Lung Cancer Secondary to ICls}

Ophthalmoplegia is the dysfunction (weakness or paralysis) of one or more muscles that control eye movement. Ptosis is the earliest and most common manifestation of ophthalmoplegia, followed by diplopia and strabismus. In this review, $53.12 \%$ of patients with ophthalmoplegia suffered ptosis, $37.50 \%$ suffered ptosis with diplopia/strabismus. Only three patients $(9.38 \%)$ complained of diplopia. Ptosis occurs when the upper eyelid droops over the eye, which in turn makes the affected eye appear smaller than normal eyes. The eyelid may droop just a little or completely covering the pupil (92). Moreover, it can be unilateral or bilateral. According to previous studies, ophthalmoplegia in lung cancer secondary to ICIs were accompanied by myasthenia gravis (MG) in all patients $(25,34-39,46,47,49-51,55-57,60$, 64, 69-76, 79, 81). Ptosis is the key manifestation of immunerelated MG, and accounts for $75 \%-78.7 \%$ of ICI-induced MG (irMG) (93-96). Only 15\% of ptosis continue to be isolated ocular complaints throughout the course of MG. MG is an autoimmune neuromuscular disease caused by antibodies directed against the postsynaptic muscle membrane. Moreover, it is reported as a life-threatening irAE with rapid deterioration shortly following ICI use $(93,97,98)$. The most common reported manifestations of ICI-related MG are ptosis (75\%), dyspnea (62\%), limb weakness (55\%), dysphagia (48\%), and diplopia (42\%) following ICI use (93). Severe muscle dysfunction with respiratory affectation, myocarditis, and/or myositis can also be detected in approximately two-thirds of individuals suffering from MG, and are the most fatal manifestations requiring mechanical support $(89,93)$. Approximately $20 \%$ of the individuals could die of MG upon an increase in respiratory dysfunction (99). In addition, the appearance of ophthalmoplegia caused by irMG can rapidly progress (96). Despite such patients with ptosis in ICI-related MG receiving discontinued ICIs and appropriate treatment with immunosuppression, their mortality rates are reportedly above $40 \%$ (100).

The high incidence of ophthalmoplegia in MG and the high mortality of life-threatening inhibitor-induced MG in lung 
TABLE 1 | Summary of reported ocular irAEs in lung cancer treated with immune checkpoint inhibitors.

\begin{tabular}{|c|c|c|c|c|c|c|c|c|c|c|c|c|c|c|c|}
\hline \multirow{2}{*}{$\begin{array}{l}\text { Patient } \\
\text { ID }\end{array}$} & \multicolumn{3}{|c|}{ Basic information } & \multirow[b]{2}{*}{ Country } & \multirow[b]{2}{*}{$\begin{array}{l}\text { Cancers } \\
\text { Diagnosis }\end{array}$} & \multirow[b]{2}{*}{$\begin{array}{l}\text { Onset } \\
\text { (d) }\end{array}$} & \multirow[b]{2}{*}{ ICls } & \multirow[b]{2}{*}{ Target } & \multirow[b]{2}{*}{ Grade } & \multicolumn{2}{|r|}{ Treatment } & \multirow[b]{2}{*}{$\begin{array}{l}\text { Follow- } \\
\text { up (d) }\end{array}$} & \multicolumn{2}{|c|}{ Outcome } & \multirow[t]{2}{*}{ Ref } \\
\hline & Ocular irAEs & Age (years) & Genders & & & & & & & ICls & Treatment & & Ocular & Systemic & \\
\hline 1 & Ophthalmoplegia & 72 & $\mathrm{~F}$ & Japan & LC & NA & Pembrolizumab & PD-1 & NA & NA & $\begin{array}{l}\text { PSL ( } 0.5 \text { mg/kg), } \\
\text { IVMP }\end{array}$ & NA & $\mathrm{CCR}$ & Alive & 46 \\
\hline 2 & Ophthalmoplegia & 77 & $\mathrm{~F}$ & Japan & NSCLC & 48 & Pembrolizumab & PD-1 & NA & NA & NA & 203 & $\mathrm{CCR}$ & Alive & 85 \\
\hline 3 & Uveitis & 69 & $\mathrm{~F}$ & USA & SCLC & 14 & $\begin{array}{l}\text { Ipilimumab and } \\
\text { nivolumab }\end{array}$ & $\begin{array}{l}\text { PD-L1+ } \\
\text { CTLA-4 }\end{array}$ & 3 & Stop & TS & 60 & $\mathrm{CCR}$ & Alive & 73 \\
\hline 4 & Ophthalmoplegia & 79 & $\mathrm{~F}$ & Belgium & LUAD & NA & Pembrolizumab & PD-1 & NA & Stop & CHO-I, PSL & 97 & $\mathrm{CCR}$ & Alive & 52 \\
\hline 5 & Uveitis & NA & NA & USA & NSCLC & NA & Pembrolizumab & PD-1 & NA & NA & NA & NA & NA & NA & 54 \\
\hline 6 & Uveitis & NA & NA & Japan & NSCLC & NA & pembrolizumab & PD-1 & NA & NA & NA & NA & NA & NA & 24 \\
\hline 7 & Dry eye & 51 & $\mathrm{M}$ & Spain & LC & 90 & Durvalumab & PD-L1 & NA & NO & TS & NA & NA & NA & 67 \\
\hline 8 & Uveitis & NA & NA & USA & NSCLC & NA & Avelumab & PD-L1 & NA & NA & NA & NA & NA & NA & 48 \\
\hline 9 & Conjunctivitis & NA & NA & Spain & NSCLC & NA & $\begin{array}{l}\text { Nivolumab and } \\
\text { Ceritinib }\end{array}$ & PD-L1 +ALK & NA & NA & NA & NA & NA & NA & 48 \\
\hline 10 & Conjunctivitis & NA & NA & Spain & NSCLC & NA & $\begin{array}{l}\text { Nivolumab and } \\
\text { Ceritinib }\end{array}$ & PD-L1 +ALK & NA & NA & NA & NA & NA & NA & 24 \\
\hline 11 & Dry eye & 72 & M & Spain & LC & 60 & Pembrolizumab & PD-1 & NA & NO & NA & NA & NA & NA & 24 \\
\hline 12 & Dry eye & 58 & M & Spain & LC & 180 & Pembrolizumab & PD-1 & NA & NO & TS & NA & NA & NA & 53 \\
\hline 13 & Uveitis & NA & NA & USA & NSCLC & NA & $\begin{array}{l}\text { Pembrolizumab } \\
\text { and CPB }\end{array}$ & $\begin{array}{l}\text { PD-1+ } \\
\text { chemotherapy }\end{array}$ & NA & NA & NA & NA & NA & NA & 24 \\
\hline 14 & Dry eye & 61 & $\mathrm{~F}$ & Spain & LC & 300 & Nivolumab & PD-L1 & NA & NO & TS, & NA & NA & NA & 24 \\
\hline 15 & Dry eye & 64 & M & Spain & LC & 30 & Durvalumab & PD-L1 & NA & Stop & TS, PSL, IVMP, PE & NA & NA & NA & 24 \\
\hline 16 & Dry eye & 70 & M & Spain & LC & 540 & Nivolumab & PD-L1 & NA & Stop & TS & NA & NA & NA & 24 \\
\hline 17 & Dry eye & 71 & M & Spain & LC & 60 & Nivolumab & PD-L1 & NA & NO & TS & NA & NA & NA & 68 \\
\hline 18 & $\begin{array}{l}\text { Orbital } \\
\text { inflammation }\end{array}$ & 70 & M & Italy & LUAD & 30 & $\begin{array}{l}\text { Durvalumab and } \\
\text { tremelimumab }\end{array}$ & $\begin{array}{l}\text { PD-L1+ } \\
\text { CTLA-4 }\end{array}$ & NA & Stop & PSL (25 mg) & NA & NA & NA & 65 \\
\hline 19 & $\begin{array}{l}\text { Giant cell } \\
\text { arteritis }\end{array}$ & 88 & $\mathrm{~F}$ & USA & NSCLC & 14 & Pembrolizumab & PD-1 & NA & NO & PSL & NA & NA & NA & 38 \\
\hline 20 & Dry eye & 50 & $\mathrm{~F}$ & Spain & LC & 150 & Pembrolizumab & PD-1 & NA & NO & TS, PSL & NA & NA & NA & 38 \\
\hline 21 & Dry eye & 79 & $\mathrm{~F}$ & Spain & LC & 30 & Pembrolizumab & PD-1 & NA & NO & TS, PSL, IVMP & NA & NA & NA & 48 \\
\hline 22 & Conjunctivitis & NA & NA & Spain & NSCLC & NA & $\begin{array}{l}\text { Nivolumab and } \\
\text { Ceritinib }\end{array}$ & PD-L1 +ALK & NA & NA & NA & NA & NA & NA & 24 \\
\hline 23 & Dry eye & 68 & $\mathrm{~F}$ & Spain & LC & 180 & Nivolumab & PD-L1 & NA & Stop & TS & NA & NA & NA & 24 \\
\hline 24 & Dry eye & 72 & $\mathrm{~F}$ & Spain & LC & 210 & $\begin{array}{l}\text { Ipilimumab and } \\
\text { nivolumab }\end{array}$ & $\begin{array}{l}\text { PD-L1+ } \\
\text { CTLA-4 }\end{array}$ & NA & NO & TS, PSL & NA & NA & NA & 67 \\
\hline 25 & Dry eye & NA & NA & USA & NSCLC & NA & Avelumab & PD-L1 & NA & NA & NA & NA & NA & NA & 24 \\
\hline 26 & Dry eye & 71 & M & Spain & LC & 210 & Pembrolizumab & PD-1 & NA & Stop & TS & NA & NA & NA & 69 \\
\hline 27 & Ophthalmoplegia & NA & NA & USA & SCLC & NA & $\begin{array}{l}\text { Ipilimumab and } \\
\text { nivolumab }\end{array}$ & $\begin{array}{l}\text { PD-L1+ } \\
\text { CTLA-4 }\end{array}$ & NA & NA & NA & NA & NA & NA & 56 \\
\hline 28 & Ophthalmoplegia & NA & NA & China & NSCLC & NA & Pembrolizumab & PD-1 & NA & NA & NA & NA & NA & NA & 41 \\
\hline 29 & $\begin{array}{l}\text { Corneal graft } \\
\text { rejection }\end{array}$ & 58 & $\mathrm{~F}$ & France & NSCLC & 126 & Nivolumab & PD-L1 & NA & Stop & TS, PSL, IVMP & 30 & Aggravation & Death & 37 \\
\hline 30 & Ophthalmoplegia & 57 & M & China & LUSC & 14 & $\begin{array}{l}\text { Ipilimumab and } \\
\text { nivolumab }\end{array}$ & $\begin{array}{l}\text { PD-L1+ } \\
\text { CTLA-4 }\end{array}$ & NA & NA & $\begin{array}{l}\text { CHO-I, PSL (1mg/ } \\
\text { kg/d), IVMP }\end{array}$ & 14 & Remission & Alive (PD) & 44 \\
\hline 31 & $\begin{array}{l}\text { Orbital } \\
\text { inflammation }\end{array}$ & 68 & $\mathrm{~F}$ & USA & NSCLC & 14 & Ipilimumab & CT+2:73LA-4 & NA & Stop & TS, PSL & 7 & Remission & Alive (PD) & 44 \\
\hline 32 & Uveitis & 54 & $\mathrm{~F}$ & USA & NSCLC & 28 & Ipilimumab & CTLA-4 & 3 & NA & TS & 42 & Remission & Death & 51 \\
\hline 33 & Ophthalmoplegia & 65 & M & Italy & LUSC & 27 & Nivolumab & PD-L1 & NA & NA & CHO-I, PSL, IVMP & 49 & Aggravation & Death & 36 \\
\hline 34 & Ophthalmoplegia & 70 & M & USA & SCLC & 16 & $\begin{array}{l}\text { Ipilimumab and } \\
\text { nivolumab }\end{array}$ & $\begin{array}{l}\text { PD-L1+ } \\
\text { CTLA-4 }\end{array}$ & NA & Stop & $\begin{array}{l}\text { PSL }(90 \mathrm{mg}) \text {, IVMP, } \\
\text { PE }\end{array}$ & 29 & Aggravation & Death & 76 \\
\hline
\end{tabular}




\begin{tabular}{|c|c|c|c|c|c|c|c|c|c|c|c|c|c|c|c|}
\hline \multirow{2}{*}{$\begin{array}{l}\text { Patient } \\
\text { ID }\end{array}$} & \multicolumn{3}{|c|}{ Basic information } & \multirow[b]{2}{*}{ Country } & \multirow[b]{2}{*}{$\begin{array}{l}\text { Cancers } \\
\text { Diagnosis }\end{array}$} & \multirow[b]{2}{*}{$\begin{array}{l}\text { Onset } \\
\text { (d) }\end{array}$} & \multirow[b]{2}{*}{ ICls } & \multirow[b]{2}{*}{ Target } & \multirow[b]{2}{*}{ Grade } & \multicolumn{2}{|r|}{ Treatment } & \multirow[b]{2}{*}{$\begin{array}{l}\text { Follow- } \\
\text { up (d) }\end{array}$} & \multicolumn{2}{|c|}{ Outcome } & \multirow[t]{2}{*}{ Ref } \\
\hline & Ocular irAEs & Age (years) & Genders & & & & & & & ICls & Treatment & & Ocular & Systemic & \\
\hline 35 & Ophthalmoplegia & 74 & M & USA & LC & NA & Pembrolizumab & PD-1 & NA & NA & $\begin{array}{l}\text { CHO-I, PSL (10 } \\
\text { mg), IVMP }\end{array}$ & 28 & Aggravation & Alive (PD) & 25 \\
\hline 36 & Ophthalmoplegia & 64 & M & USA & NSCLC & NA & Durvalumab & PD-L1 & NA & NA & PSL & NA & Aggravation & Death & 37 \\
\hline 37 & Ophthalmoplegia & 65 & M & China & LUSC & 53 & Nivolumab & PD-L1 & NA & NO & $\begin{array}{l}\text { CHO-I, PSL (1mg/ } \\
\mathrm{kg}) \text {, }\end{array}$ & 27 & Aggravation & Alive (PD) & 34 \\
\hline 38 & Ophthalmoplegia & 76 & $\mathrm{~F}$ & Japan & LUAD & 26 & Nivolumab & PD-L1 & NA & Stop & $\begin{array}{l}\text { PSL (10mg), IVMP, } \\
\text { PE }\end{array}$ & 65 & Remission & Death & 74 \\
\hline 39 & Ophthalmoplegia & 68 & $\mathrm{~F}$ & USA & NSCLC & 70 & Nivolumab & PD-L1 & NA & Stop & $\begin{array}{l}\text { CHO-I, PSL (60 } \\
\text { mg) }\end{array}$ & 18 & Aggravation & Death & 79 \\
\hline 40 & Ophthalmoplegia & 61 & M & France & NSCLC & NA & Nivolumab & PD-L1 & NA & Stop & IVMP & 77 & Remission & Death & 78 \\
\hline 41 & Uveitis & 60 & $\mathrm{~F}$ & USA & LC & NA & $\begin{array}{l}\text { Ipilimumab and } \\
\text { nivolumab }\end{array}$ & $\begin{array}{l}\text { PD-L1+ } \\
\text { CTLA-4 }\end{array}$ & NA & NO & $\begin{array}{l}\text { PSL, } \\
\text { immunosuppressive }\end{array}$ & 84 & Remission & Alive (PD) & 50 \\
\hline 42 & Ophthalmoplegia & 73 & $\mathrm{~F}$ & Japan & LUSC & 140 & Nivolumab & PD-L1 & NA & NO & $\begin{array}{l}\text { CHO-I, PSL (20 } \\
\text { mg) }\end{array}$ & 120 & Aggravation & Alive (PD) & 84 \\
\hline 43 & Dry eye & 36 & $\mathrm{~F}$ & France & LC & 39 & Pembrolizumab & PD-1 & NA & NA & TS, PSL (10 mg) & 60 & Remission & Alive & 57 \\
\hline 44 & Ophthalmoplegia & 73 & M & Japan & LUAD & 23 & Pembrolizumab & PD-1 & NA & NA & PSL (20 mg), IVMP & 120 & Remission & Alive & 62 \\
\hline 45 & $\begin{array}{l}\text { Corneal } \\
\text { perforation }\end{array}$ & 68 & M & Belgium & LUAD & 126 & Pembrolizumab & PD-1 & NA & Stop & $\begin{array}{l}\text { TS, Surgery, PSL } \\
(32 \mathrm{mg})\end{array}$ & 30 & Remission & Alive & 47 \\
\hline 46 & Uveitis & 71 & M & Japan & LUSC & 14 & Pembrolizumab & PD-1 & 3 & Stop & TS, PSL (70 mg) & 21 & Remission & Alive & 81 \\
\hline 47 & Ophthalmoplegia & 69 & $\mathrm{~F}$ & Japan & NSCLC & NA & Nivolumab & PD-L1 & NA & NA & PSL, IVMP & 36 & Remission & Alive & 66 \\
\hline 48 & Retinopathy & 40 & M & USA & NSCLC & 13 & Atezolizumab & PD-L1 & NA & Stop & NA & 21 & Remission & Alive & 86 \\
\hline 49 & Retinopathy & 64 & M & Spain & NSCLC & 600 & Durvalumab & PD-L1 & NA & NO & PSL (30 mg), IVMP & 60 & Remission & Alive & 87 \\
\hline 50 & Uveitis & 53 & M & USA & NSCLC & 19 & Nivolumab & PD-L1 & 3 & Stop & $\begin{array}{l}\text { Surgery, PSL (1mg/ } \\
\mathrm{kg})\end{array}$ & 9 & Remission & Alive & 80 \\
\hline 51 & Uveitis & 68 & M & USA & LUAD & NA & Atezolizumab & PD-L1 & 4 & Stop & NA & 90 & Remission & Alive & 35 \\
\hline 52 & Ophthalmoplegia & 65 & M & USA & NSCLC & 14 & Nivolumab & PD-L1 & NA & Stop & CHO-I, & 42 & Remission & Alive & 45 \\
\hline 53 & Uveitis & 54 & $\mathrm{~F}$ & Japan & LC & NA & Nivolumab & PD-L1 & 3 & NO & TS, PSL (30mg) & 135 & Remission & Alive & 33 \\
\hline 54 & Optic Neuritis & 76 & M & Spain & NSCLC & 72 & pembrolizumab & PD-1 & NA & NA & $\begin{array}{l}\mathrm{PSL}(0.5 \mathrm{mg} / \mathrm{Kg} / \\
\text { day), IVMP }\end{array}$ & 21 & Remission & Alive & 66 \\
\hline 55 & Retinopathy & 50 & M & USA & NSCLC & 13 & Atezolizumab & PD-L1 & NA & Stop & NA & 21 & Remission & Alive & 30 \\
\hline 56 & Amaurosis fugax & 84 & M & USA & NSCLC & NA & Nivolumab & PD-L1 & NA & NA & NA & NA & Remission & Alive & 43 \\
\hline 57 & Uveitis & 61 & $\mathrm{~F}$ & USA & NSCLC & 60 & Durvalumab & PD-L1 & 4 & NO & TS & 30 & Remission & Alive & 29 \\
\hline 58 & Uveitis & 63 & $\mathrm{~F}$ & France & NSCLC & 36 & Nivolumab & PD-L1 & 3 & NA & TS & 42 & Remission & Alive & 63 \\
\hline 59 & Uveitis & 61 & M & Japan & NSCLC & 63 & Pembrolizumab & PD-1 & NA & Stop & PSL & NA & Remission & Alive & 42 \\
\hline 60 & Retinopathy & 64 & $\mathrm{~F}$ & USA & LUAD & 7 & Nivolumab & PD-L1 & NA & Stop & PSL (60mg) & 21 & Remission & Alive & 46 \\
\hline 61 & Ophthalmoplegia & 53 & M & Japan & NSCLC & 27 & Nivolumab & PD-L1 & NA & NA & PSL (30mg), IVMP & 49 & Remission & Alive & 60 \\
\hline 62 & Ophthalmoplegia & 83 & M & Japan & LUSC & 38 & Pembrolizumab & PD-1 & NA & NA & CHO-I,PSL (20 mg) & 51 & Remission & Alive & 38 \\
\hline 63 & Ophthalmoplegia & 65 & M & Espada & LUAD & - & Nivolumab & PD-L1 & NA & Stop & CHO-I & NA & Remission & Alive & 46 \\
\hline 64 & Ophthalmoplegia & 46 & $\mathrm{~F}$ & Japan & NSCLC & 30 & Nivolumab & PD-L1 & NA & NA & NA & 14 & Remission & Alive & 55 \\
\hline 65 & Ophthalmoplegia & 77 & $\mathrm{~F}$ & Japan & LUAD & 49 & Pembrolizumab & PD-1 & NA & NA & PSL, IVMP & 209 & Remission & Alive & 25 \\
\hline 66 & Optic Neuritis & 74 & M & USA & NSCLC & NA & Pembrolizumab & PD-1 & NA & Stop & NA & NA & Remission & Alive & 46 \\
\hline 67 & Ophthalmoplegia & 78 & M & Japan & NSCLC & 38 & Pembrolizumab & PD-1 & NA & NA & PSL (80mg), IVMP & 91 & Remission & Alive & 46 \\
\hline 68 & Ophthalmoplegia & 83 & M & Japan & NSCLC & 28 & Pembrolizumab & PD-1 & NA & NA & PSL (20mg) & 42 & Remission & Alive & 71 \\
\hline 69 & Ophthalmoplegia & 66 & M & China & LUAD & 21 & Sintilimab & PD-1 & NA & NA & $\begin{array}{l}\text { CHO-I, PSL (60 } \\
\text { mg), IVMP, IVlg, PE }\end{array}$ & 90 & Remission & Alive & 61 \\
\hline 70 & Uveitis & 55 & $\mathrm{~F}$ & USA & LC & 42 & Pembrolizumab & PD-1 & 2 & NA & TS & 42 & Remission & Alive & 83 \\
\hline 71 & Conjunctivitis & 67 & M & Switzerland & LUAD & 182 & Nivolumab & PD-L1 & NA & NO & TS & NA & Remission & Alive & 82 \\
\hline 72 & Optic Neuritis & 64 & M & Japan & NSCLC & 365 & Pemetrexed & PD-L1 & NA & NA & PSL (30 mg), IVMP & 3 & Remission & Alive & 70 \\
\hline
\end{tabular}




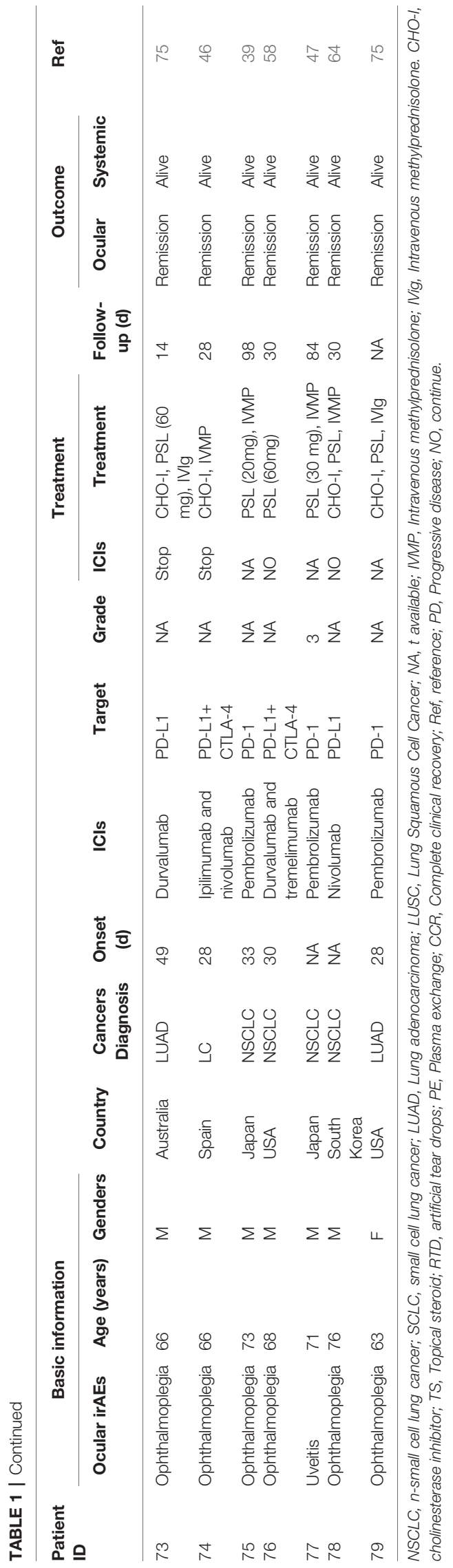

cancer necessitate an increase in ophthalmoplegia vigilance. This will ensure the timely identification of irMG signs and early treatment, particularly in the early stages of irAEs. In this review, all recruited patients with ophthalmoplegia were diagnosed with MG in lung cancer following the use of ICIs. It could be unilateral (57.89\%) or bilateral (42.11\%), and the average onset time of ophthalmoplegia was 37.73 days following ICI initiation (Table 2). There were $66.67 \%$ men, and $66.67 \%$ patients were older than 65 years. Ptosis accounted for $90.63 \%$ of the patients with ICI-related ophthalmoplegia in lung cancer, followed by diplopia and strabismus.

It is difficult to make a definitive diagnosis of ophthalmoplegia in MG based on the clinical characteristics (101). However, electrophysiology and detectable antibodies could facilitate the diagnosis (102). The edrophonium test, ice pack test, antibody assays (acetylcholine receptor autoantibodies; anti-muscle-specific tyrosine kinase auto-antibodies; low-density lipoprotein receptor-related protein 4), and neurophysiological tests (repetitive nerve stimulation and single-fibre electromyography) are the necessary examinations for the diagnosis of ptosis in MG (Table 3). Ophthalmoplegia in MG in lung cancer secondary to ICIs should be differentiated from other causes, which might also result in ptosis, including central disorders of ocular motility, congenital ptosis, inherited ptosis-associated syndrome, aponeurotic ptosis, and ptosis caused by local eye problems or muscles $(103,104)$.

\section{Uveitis in Lung Cancer Secondary to ICls}

Uveitis describes a group of inflammatory diseases that produce swelling and destroy the uveal tract. The uveal tract consists of a pigmented, highly vascular, and loose fibrous tissue, prone to immune disorders. It can be divided into three anatomical regions as follows: anterior (involves the iris), intermediate (involves the vitreous humor), posterior (involves the choroid), and panuveitis (widespread involvement across anatomical regions) by the Standardisation of Uveitis Nomenclature Working Group. The aforementioned types of uveitis have varied clinical characteristics, diagnostic tests, and treatment (Table 3). Symptoms of pain, redness, photophobia, blurred vision, or floaters can be detected in patients with uveitis. Anterior uveitis is characterized by anterior chamber cells and flare, keratic precipitates, posterior synechiae, iris nodules, and cataracts. The clinical features of intermediate uveitis include grey-white fibrovascular plaques (snowbanks), the presence of cells suspended in the vitreous, vitreous haze, and inflammatory aggregates within the vitreous. In contrast, the characteristics of posterior uveitis include lesions within the retina or choroid, commonly known as white spots. All clinical features of the above-mentioned three types of uveitis were revealed in panuveitis (Table 3). Moreover, Vogt-Koyanagi-Harada disease is a common ocular irAE associated with ICIs $(45,58,105)$. It is a type of bilateral granulomatous uveitis, associated with exudative retinal detachment and extraocular manifestations, such as pleocytosis in the cerebrospinal fluid and, in some cases, vitiligo, poliosis, alopecia, and dysacusis.

The majority of previously described uveitis on ICI therapy exhibited relatively mild to moderate severity, with $\leq 2+$ anterior 
TABLE 2 | Comparison of the ophthalmoplegia, uveitis and other ocular irAEs secondary to ICls in lung cancer.

\begin{tabular}{|c|c|c|c|c|c|c|}
\hline & Total (\%) & Ophthalmoplegia (\%) & $\begin{array}{c}\text { B } \\
\text { Uveitis (\%) }\end{array}$ & $\begin{array}{c}\text { C } \\
\text { Dry eye (\%) }\end{array}$ & $\begin{array}{c}\text { D } \\
\text { Others (\%) }\end{array}$ & $\begin{array}{c}\text { P value } \\
\text { Ophthalmoplegia VS } \\
\text { other irAEs (Uveitis, Dry } \\
\text { eye and Others) }\end{array}$ \\
\hline NO. & 79(100.00) & $32(40.51)$ & $16(20.25)$ & $14(17.72)$ & $17(21.52)$ & \\
\hline Age & $66.22 \pm 9.95$ & $69.03 \pm 8.22$ & $61.67 \pm 6.52$ & $63.31 \pm 11.40$ & $66.79 \pm 11.94$ & \\
\hline Gender & & & & & & (Male VS Female) \\
\hline Male & $42(53.16)$ & $20(62.5)$ & $5(31.25)$ & $7(50)$ & $10(58.82)$ & 8.00E-02 \\
\hline Female & $27(34.18)$ & $10(31.25)$ & $7(43.75)$ & $6(42.86)$ & $4(23.53)$ & \\
\hline NA & $10(12.66)$ & $2(6.25)$ & $4(25)$ & $1(7.14)$ & $3(17.65)$ & \\
\hline Age & & & & & & $(\leq 65$ VS >65) \\
\hline$\leq 65$ & $30(37.97)$ & $10(31.25)$ & $8(50)$ & $6(42.86)$ & $6(35.29)$ & 2.46E-02 \\
\hline$>65$ & 39 (49.37) & $20(62.5)$ & $4(25)$ & $7(50)$ & $8(47.06)$ & \\
\hline NA & $10(12.66)$ & $2(6.25)$ & $4(25)$ & $1(7.14)$ & $3(17.65)$ & \\
\hline Onset(d) & $86.31 \pm 119.81$ & $37.73 \pm 26.10$ & $34.50 \pm 18.18$ & $159.92 \pm 136.79$ & $130.17 \pm 136.79$ & \\
\hline Ethnicity & & & & & & (Caucasian VS Asian) \\
\hline Caucasian & 59 (74.68) & $18(56.25)$ & $11(68.75)$ & $14(100)$ & $16(94.12)$ & $1.21 \mathrm{E}-06$ \\
\hline Asian & $20(25.32)$ & $14(43.75)$ & $5(31.25)$ & $0(0)$ & $1(5.88)$ & \\
\hline Unilateral or Bilateral & & & & & & (Unilateral VS Bilateral) \\
\hline Unilateral & $28(35.44)$ & $11(34.38)$ & $10(62.5)$ & $0(0)$ & $7(41.18)$ & $1.46 \mathrm{E}-01$ \\
\hline Bilateral & $16(20.25)$ & $8(25.00)$ & $2(12.5)$ & $0(0)$ & $6(35.29)$ & \\
\hline NA & $35(44.3)$ & $13(40.63)$ & $4(25.00)$ & $14(100)$ & $4(23.53)$ & \\
\hline $\mathrm{ICls}$ & & & & & & (PD-1 VS PDL-1 VS PD-L1+CTLA4) \\
\hline PD-1 & $29(36.71)$ & $13(40.63)$ & $6(37.5)$ & $6(42.86)$ & $4(23.53)$ & 2.07E-01 \\
\hline PD-L1 & $35(44.3)$ & $14(43.75)$ & $6(37.5)$ & $7(50)$ & $8(47.06)$ & \\
\hline PD-L1+CTLA4 & $9(11.39)$ & $5(15.63)$ & $2(12.5)$ & $1(7.14)$ & $1(5.88)$ & \\
\hline Others & $6(7.59)$ & $0(0)$ & $2(12.5)$ & $0(0)$ & $4(23.53)$ & \\
\hline Outcome(Ocular) & & & & & & (Aggravation VS Remission) \\
\hline Aggravation & $9(11.39)$ & $7(21.88)$ & $0(0)$ & $1(7.14)$ & $1(5.88)$ & 3.98E-04 \\
\hline Remission & $47(59.49)$ & $23(71.88)$ & $12(75)$ & $1(7.14)$ & $11(64.71)$ & \\
\hline NA & $23(29.11)$ & $2(6.25)$ & $4(25)$ & $12(85.71)$ & $5(29.41)$ & \\
\hline Survival state & & & & & & (Death VS Alive) \\
\hline Death & $8(10.13)$ & $7(21.88)$ & $1(6.25)$ & $0(0)$ & $0(0)$ & 1.82E-09 \\
\hline Alive & $48(60.76)$ & $23(71.88)$ & $11(68.75)$ & $2(14.29)$ & $12(70.59)$ & \\
\hline NA & 23 (29.11) & 2 (6.25) & $4(25)$ & 12 (85.71) & $5(29.41)$ & \\
\hline
\end{tabular}

NO., number; $d$, days; NA, not available; $d$, days; NS, no significant difference; CCR, Complete clinical recovery.

chamber cells and vitreous cells $(28,30,77)$. In our review, 16 patients with uveitis and six patients did not manifest the detailed clinical features. Among the remaining patients with lung cancer, $70.00 \%$ were classified as grade 3 with anterior uveitis, comprising $\geq 3+$ cells or intermediate posterior or panuveitis, based on the Common Terminology Criteria for Adverse Events (Version 5.0). While a total of $20.00 \%$ were classified as grade 4 , only $10.00 \%$ were classified as grade 1 (Table 2). The average onset days of uveitis was 34.50 days on ICIs (Tables 2, 3). There were $41.67 \%$ male patients, and $33.33 \%$ patients were older than 65 years. Moreover, $83.33 \%$ cases were unilateral.

Ocular examination including slit-lamp examination, ultrasound biomicroscopy, optical coherence tomography (OCT), ophthalmoscopy, fluorescein angiography or indocyanine green angiography are adapted for the diagnosis of uveitis. Diagnosis could be made based on clinical evidence including the clinical features and positive signs for auxiliary examination. Uveitis in lung cancer secondary to ICIs need to be differentiated from other disorder which might to presents as uveitis, including: infectious uveitis due to tuberculosis, syphilis or toxoplasma or other bacteria, autoimmune related uveitis, masquerade uveitis (105) (Table 3).

\section{Dry Eye in Lung Cancer Secondary to ICls}

Dry eye disease is a multifactorial disorder of the tears and ocular surface, that caused by tear deficiency or excessive tear evaporation (106). It has been classified as dry eye with reduced tear production (occupying approximately 10\%) and dry eye with increased evaporation of the tear film (hyperevaporative disorders) (107). Dysfunction of the meibomian glands is the primary cause of the hyperevaporative disorders and occupied more than $80 \%$ of the patients with dry eye (108). Dryness, redness, fatigue, photophobia, a sensation of burning, stinging or foreign body or pruritus could be detected. Pronounced conjunctival redness and punctate epithelial erosions of the cornea are typical clinical manifestations of dry eye (107). Inflammation of the lid margin or meibomian glands could be detected in dry eye caused by hyperevaporative disorders. In addition, dry eye could be one of the manifestations of systemic syndrome, such as Sjögren's syndrome. Sjögren's syndrome is an intractable autoimmune disease, characterized by dry eye, dry mouth, and extra glandular syndrome (109). In this review, patients with sjögren's syndrome consisted of $92.86 \%$ of dry eye following ICI in lung cancer.

A comprehensive history (symptoms, systemic diseases and medication history), tear film break-up time with fluorescein, schirmer test, examination of the eyelid margins and meibomian 


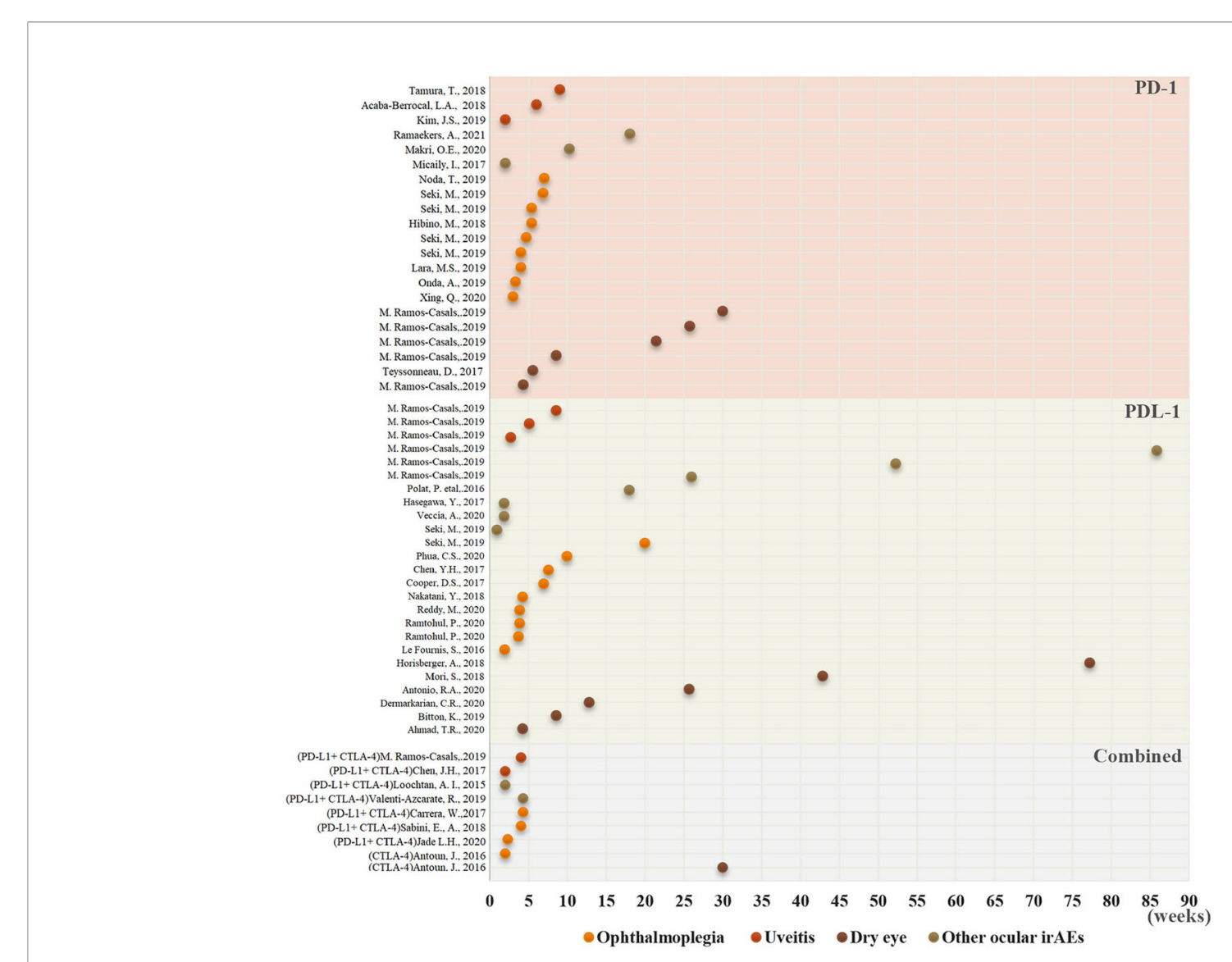

FIGURE 2 | The onset time of the distribution of different ocular irAEs in lung cancer following ICI use. The onset time of ocular irAE detection has been recorded as a dot. Yellow, ophthalmoplegia; dark yellow, uveitis; brown, dry eye; and darkgray, other ocular irAEs.

gland orifices with expression of meibomian secretion could be conducted based on the diagnostic guidelines were published in 2007 by the Dry Eye Workshop $(107,110)$. In addition, screening for autoimmune diseases should be done as well, especially for Sjögren syndrome (111). The Gum test, the unstimulated whole saliva, saxon test, the labial salivary glands biopsy, and parotid glands biopsy are helpful for the diagnosis of Sjögren syndrome (109).

\section{Conjunctivitis}

Conjunctivitis caused by ICIs are the inflammation of conjunctiva which covers the inner surface of the eyelids and the white part of the eyeball. The blood vessels are enlarged and become more prominent in conjunctivitis. Red eye is the most common signs of conjunctivitis. Itchy, watery, burning or stinging eye and foreignbody sensation could be detected in patients with conjunctivitis. Ophthalmologist could give a diagnosis of conjunctivitis based on the Slit-lamp examination. Sodium hyaluronate, antihistamine eye drops or topical corticosteroids can help with symptoms of conjunctivitis after use of ICIs.

\section{Corneal Perforation}

Corneal perforation is the thinning and perforation of the cornea. Red eyes, severe pain, foreign-body sensation, tears, thick discharge, blurry vision, pain when looking at bright lights, swollen eyelids, and a white round spot on the cornea that is visible to the naked eye. The classic signs are shallowing or flattening of the anterior chamber, aqueous leakage, brown pigment from the iris in the wound could be detected. For the treatment of the corneal perforation, the first step is to discontinue the ICIs (112). Medical treatment is the second therapeutic step, including artificial tear drops, corticosteroids and cyclosporine. Timely diagnosis and prompt medical treatment could improve the rate of the surgical success (62, 112). Several surgical strategies could be used and it depends on the size, position, and depth of the ulceration $(112,113)$. The surgical management of corneal perforation includes corneal gluing, Collagen cross-linking with photo-activated riboflavin, Amniotic membrane transplantation, Conjunctival flap transplantation, Corneal transplantation.

\section{Corneal Graft Rejection}

Corneal graft rejection is a complex immune-mediated response, which leads to corneal graft decompensation (114). The rejection can occur in all of the layers of the cornea (epithelium, stroma and endothelium). Pain, redness, and decreased vision could be present in patients suffering corneal graft rejection. Conjunctival 


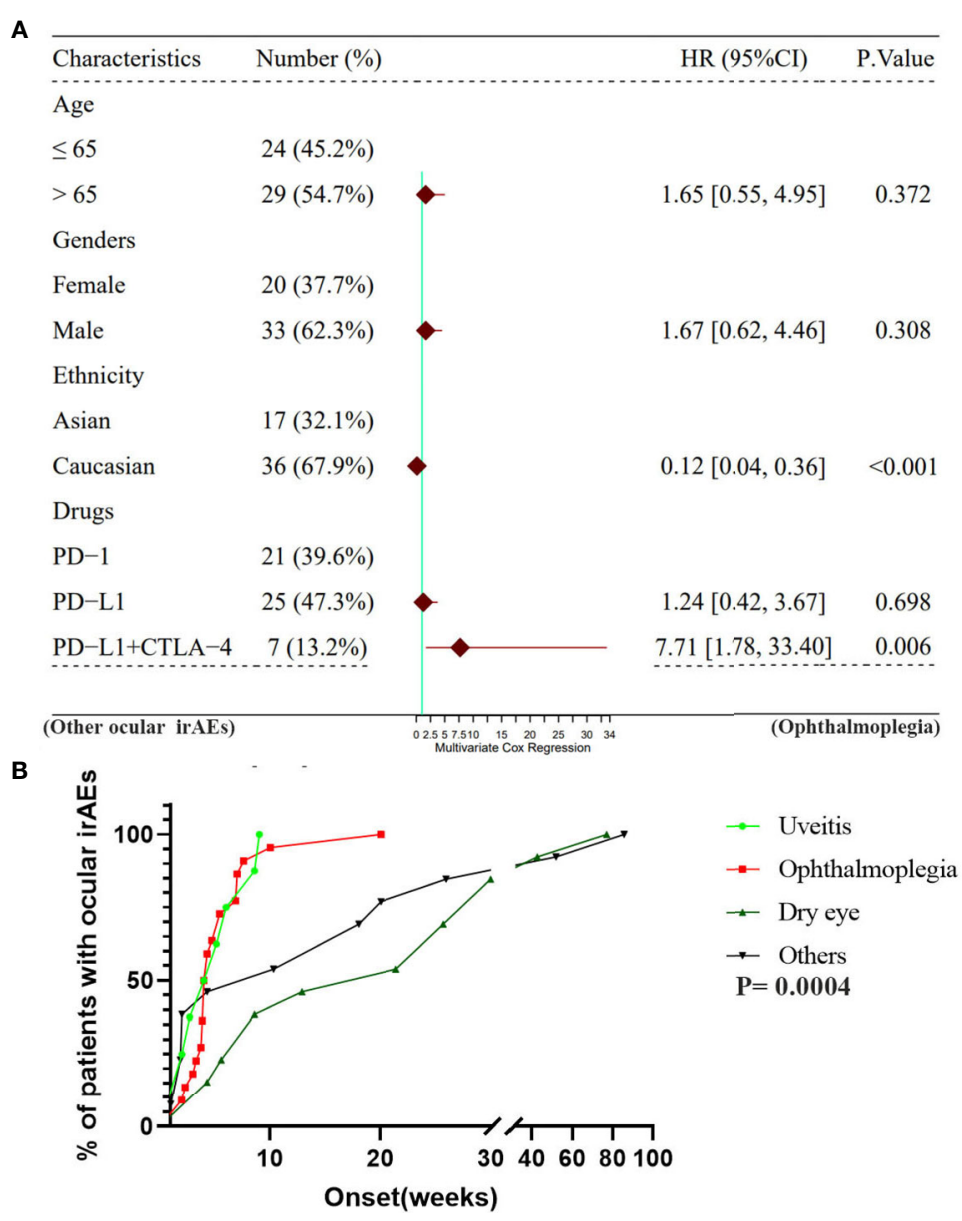

FIGURE 3 | (A) A multivariate cox regression analysis for the ocular irAEs among age, gender, ethnicity, ICls drugs. (B) A comparison of the onset time of ocular irAEs among ophthalmoplegia, uveitis, dry eye, and other ocular irAEs.

hyperemia, keratic precipitates, opacity and edema of corneal graft could be detected. It is not difficult to give diagnosis of corneal graft rejection based on the slit-lamp microscope. Prevention, early detection, and rapid management are crucial for the management of graft rejection $(114,115)$. Stop the ICIs is the essential which have been recommended in the previous study (41). Corticosteroids (Topical and systemic corticosteroids, intravenous pulsed corticosteroid therapy), cytotoxic agents (azathioprine), cyclosporin A have been used for management of corneal graft rejection (114).

\section{Retinopathy}

Retinopathy after use of ICIs might be caused by abnormal crossreactivity of autoantibodies directed to retinal antigens. Vision loss, scotomas, photopsia, nyctalopia could be found in patients with retinopathy (116). Optical coherence tomography, fundus autofluorescence, visual field and electrophysiology could help us to detect to lesion on the retina. Medical history and physical exam findings are important for us to determine the risk factors of immune related retinopathy. High suspicion and early diagnosis and treatment are essential to reduce the risk of irreversible immune damage to retinal cells. Systemic and/or topical corticosteroids, immunomodulators (cyclosporine, infliximab, et al), biologics (rituximab, alemtuzumab, et al), intravenous immunoglobulin (IVIG) and plasmapheresis have been advocated for the treatment of immune related retinopathy (116-118).

\section{Optic Neuritis}

Typically, optic neuritis is unilateral. Eye pain, vison loss, the loss of the visual field, flashing lights could be detected in patients with optic neuritis. Ocular examination including slit-lamp examination, pupillary light reaction test, optical coherence tomography, visual field test, visual evoked response is adapted for the diagnosis of optic neuritis (119, 120). High-dose corticosteroids is effective for the treatment of optic neuritis. For the steroid-resistant optic neuritis, plasma exchange is needed (119).

\section{Amaurosis Fugax}

Amaurosis fugax refers to transient visual loss caused by the temporary ceasing of the retinal blood flow $(121,122)$. The time 
TABLE 3 | The clinical characteristics, diagnosis, and treatment for ocular irAEs on ICls therapy in lung cancer.

Ocular irAEs

Ophthalmoplegia $\quad$ Ocular: ptosis, diplopia, blurred vision

Systemic: Difficulty in breathing, swallowing chewing, walking, using arms or hands, or holding up head.

Uveitis Anterior uveitis Pain, redness, photophobia, blurred vision: Anterior chamber cells and flare; keratic

precipitates, posterior synechiae, iris nodules and cataract.

$\begin{array}{ll}\text { Intermediate } & \text { Floaters and blurred vision; } \\ \text { uveitis } & V \text { itreous cells, vitreous haze, 'snowbanks' (grey- }\end{array}$

Posterior uveitis 'Floaters', blurred vision and blind spots; Unifocal, or multifocal, generally white lesions.

Panuveitis

All clinical characteristics of the anterior, intermediate and posterior uveitis

Dry eye

Conjunctivitis

Corneal perforation

Red, itchy, watery, burning or stinging eye and foreign-body sensation

Red eyes, severe pain, foreign-body sensation, tears, blurry vision, swollen eyelids

White spot on cornea, edema of cornea

Corneal graft rejection Pain, redness, and decreased vision, conjunctival hyperemia, keratic precipitates, opacity and edema of corneal graft

Retinopathy

Vision loss, scotomas, photopsia, nyctalopia

Optic neuritis Eye pain, vison loss, the loss of the visual field flashing lights

Amaurosis fugax

Transient visual loss
OCT, FFA, VF and electrophysiology

1. Edrophonium test

2. The ice pack test

3.Antibody assays (ACht Ab; Anti-MuSK Ab; LRP4

4.Neurophysiological tests (RNS and SfEMG)

Slit-lamp examination

Slit-lamp examination; Anterior segment OCT

Ophthalmoscopy; OCT; FFA

All diagnosis test of the anterior, intermediate and posterior uveitis

Ocular: Tear film break-up time with fluorescein, Schirmer test, examination

of the eyelid margins and meibomian gland orifices with expression of meibomian secretion

(For dry eye in Sjögren syndrome) Systemic: The Gum test, the

unstimulated whole saliva, Saxon test, the labial salivary glands biopsy, and parotid glands biopsy

Slit-lamp microscope

Slit-lamp microscope

Slit-lamp microscope

Slit-lamp microscope, pupillary light reaction test, OCT, visual field test, visual evoked response

Comprehensive ocular examination and assessment of cardiovascular system (electrocardiogram, magnetic resonance angiography, blood test)
1. Cholinesterase inhibitor

Systemic Corticosteroids

3. IVMP, IVig, PE, Stop ICls when necessary

1. Topical Corticosteroids

2. Topical mydriatics

1. Topical Corticosteroids

2. Systemic Corticosteroids

1. Topical corticosteroids

2. Systemic corticosteroids

3. Subconjunctival/Periocular corticosteroids

4. IVMP, IVig, PE, Stop ICls when necessary

All diagnosis treatment of the anterior, intermediate and posterior uveitis

Artificial tears, Autologous serum eyedrops, Topica corticosteroid, Topical Cyclosporine A

1. Topical sodium hyaluronate, antihistamine eye drops

1. Discontinue the ICls

2. Topical artificial tear drops, corticosteroids and

cyclosporine;

3. IVMP, IVig, PE when necessary

1. Discontinue the ICls

2. Topical artificial tear drops, corticosteroids and

cyclosporine;

3. IVMP, IVig, PE,cytotoxic agents, cyclosporin A when necessary

1. Topical Corticosteroids

2. Systemic Corticosteroids

3. IVMP, IVig, PE when necessary

1. Systemic corticosteroids

2. Subconjunctival/Periocular corticosteroids

3. IVMP, IVig, PE when necessary

Control and treat potential vascular risk factors 
of amaurosis fugax could be last 2-30 minutes. Hypoperfusion, vasospasm, thromboembolism from a carotid plaque, elevated plasma viscosity and cerebrovascular disease could be pathogenic causes of amaurosis fugax (121). Comprehensive ocular examination and assessment of cardiovascular system is essential. An electrocardiogram, Magnetic resonance angiography, blood test and so on should be performed. The primary goal of treatment is to control and treat potential vascular risk factors (121).

\section{Giant Cell Arteritis}

Giant cell arteritis is primary vasculitis which mostly invades large vessels. The clinical characteristics is with strong heterogeneity, the common systemic manifestations are headaches, scalp tenderness, jaw claudication, vision loss, absent pulses and limb claudication $(123,124)$. About twothirds patients could be detected ocular symptoms. Blurred vision is the most common manifestations (125). Diplopia, amaurosis fugax and blindness could be also present. Comprehensive ocular examination including ophthalmoscopy, FFA and ICGA are needed. Additionally, biopsy of the temporal artery, high-resolution color doppler ultrasound of the cranial and axillary arteries, MRI, CT scan need to be recommended for the diagnosis of Giant cell arteritis. Glucocorticoids has been considered as the primary treatment for Giant cell arteritis. Tocilizumab is also been approved by the FDA (124).

\section{Orbital Inflammation}

Orbital inflammation is characterized by infiltration of inflammatory cells, which is confined to the orbit, but may extend to the extraorbital area. Categories of orbital inflammation include dacryoadenitis, myositis, perineuritis of the optic nerve, periscleritis, diffuse sclerosing inflammation, and orbital apex inflammation. Eye pain, proptosis, decreased visual acuity, and eye movement restriction that may result in diplopia were the most common symptoms. Obvious orbital masses can be found by radiologic examination (126). Laboratory evaluation, Orbital ultrasound, Computed Tomography (CT), and Magnetic Resonance Imaging (MRI) may aid in the diagnosis when combined with clinical findings (127). Current therapeutic methods available for orbital inflammation include corticosteroids, nonspecific steroid-sparing agents(methotrexate, cyclosporin-A et al), biologic agents (infliximab, adalimumab and so on) and radiation therapy (128).

\section{CONTRIBUTORY FACTORS OF OCULAR irAEs IN LUNG CANCER SECONDARY TO ICIS}

\section{Ethnicity}

Asian and Caucasian patients with lung cancer have different epidemiology, molecular profiles, and genetic susceptibilities $(129,130)$. Different incidences of irAEs secondary to ICIs could be detected between Asian populations and Western populations. The irAEs of grades 3-5 also present different prevalence rates between Asian and Western populations 
(131). Moreover, researchers could also detect differences in ocular irAEs associated with ICIs. A review of the IRIS Registry reported on a higher frequency of ocular irAEs in the Black population (9.7\%, six of 62 patients) than that in the White population (3.5\%, 91 of 2623 patients) (30). In addition, the Black population demonstrated a higher rate of ICI-related uveitis than their White counterparts.

In this review, among all patients with lung cancer and ocular side effects, $68.12 \%$ and $31.88 \%$ were Caucasians and Asians, respectively. The majority of patients with ICI-related ocular irAEs were reported in America (42.03\%) and Japan (26.09\%). The incidence of ophthalmoplegia was 43.75\% (14/32) in Asians, compared to $12.77 \%(6 / 47)$ in Caucasians (Table 2, Figure 3, and Figure S1). Based on the multivariate Cox regression analysis, ethnicity was presented as an important factor that influenced ocular irAEs (Figure 3). Ophthalmoplegia was more frequently detected in Asians than in Caucasians (Table 2 and Figure 3). However, no significant difference has been detected in the onset time of ocular irAEs in lung cancer (Figure S1). Thus, ethnicity could be an important factor in the type of ocular irAEs following ICI use.

\section{Types of ICls}

CTLA-4 inhibitors are reportedly associated with a higher frequency of irAEs and distinct profiles, compared to PD-1 inhibitors $(132,133)$. Moreover, the proportion of grade 3-4 irAEs is higher with CTLA-4 inhibitors (31\%), compared to PD1 inhibitors $(10 \%)(132,134)$. Data from a recent clinical trial reported on lower overall incidence of AEs in monotherapy with ICIs than that of combination therapy in NSCLC $(89,135)$. Furthermore, PD-L1 inhibitors combined with chemotherapy have a higher incidence of irAEs than monotherapy with PD-L1 inhibitors (98.2\% vs. 70.9\%, respectively) in NSCLC $(92,116,117)$. Researchers have also identified differences in the distribution and incidence of ocular irAEs. Ocular surface adverse effects occur more frequently with PD-L1 (31). Uveitis is more likely to occur in patients following ICI therapy with CTLA-4 inhibition than in those with PD1 inhibition $(14,30,136)$. In addition, ocular myasthenia reveals the highest association with nivolumab, followed by pembrolizumab (136).

Based on the reported ICI-related ocular irAEs, $44.30 \%$ of the patients with lung cancer were treated with PD-L1 inhibitors. In contrast, $36.71 \%$ and $11.39 \%$ were treated with PD- 1 inhibitors and PD-L1 plus CTLA4 inhibitors, respectively. There was no significant difference in the distribution of ocular irAEs between PD-L1 inhibitors and PD-1 inhibitors. Nonetheless, significant differences were detected between monotherapy (PD-L1/PD-1 inhibitors) and combined therapy (PD-L1 plus CTLA4 inhibitors) (Table 2 and Figure 3). Based on the multivariate Cox regression analysis, combined therapy was significantly more prone to ophthalmoplegia than monotherapy (Figure 3). The average onset time of ICI-related ocular irAEs with combined therapy with PD-L1 plus CTLA4 inhibitors (6.98 weeks) was shorter than that in patients treated with PD-1 (8.88 weeks) and PD-L1 inhibitors (17.47 weeks). However, the difference was insignificant (Figure S1).

\section{Pre-Existing Disorders}

Pre-existing disorders are the most important risk factors for ICI-induced irAEs $(137,138)$. Moreover, $27 \%$ of the patients with a history of autoimmune diseases could suffer from exacerbations of the autoimmune condition, which requires systemic treatment following the use of ICIs (30). With a history of non-ophthalmic autoimmune diseases, ocular irAEs could be detected in $27-40 \%$ patients undergoing ICI treatment $(30,139)$. The incidence of ICI-related uveitis could be as high as $51.10 \%$ in patients with prior uveitis diagnosis, and up to $36.40 \%$ of patients experience various neuro-ophthalmic complications (139). In addition, approximately $20.00 \%$ of the patients with Sicca/Sjögren's syndrome following the use of PD-1/PD-L1 checkpoint inhibitors reportedly have a history of previous autoimmune diseases (personal or familial), thereby indicating a predisposing immunogenetic background, according to the data from the International Immuno Cancer Registry (ICIR) (24). In this review, one patient with lung cancer reported a history of inactive uveitis. Following ICI use for 2 months, uveitis with $2+$ anterior chamber cells and fine keratic precipitates were detected in both eyes (43). Therefore, pre-existing autoimmune diseases could play a non-negligible role in the occurrence of ICIrelated ocular irAEs, thus warranting more attention to medical history.

\section{Other Factors \\ Age}

According to a retrospective study, patients older than 70 years demonstrated comparable efficacy and safety outcomes for ICIs than younger patients (140). Better long-term outcomes were detected in older patients $(140,141)$. Furthermore, irAEs followed by ICIs had similar efficacy outcomes. Grade 3-4 irAEs rates did not reveal statistical differences between older ( $11 \%, \geq 70$ years) and younger patients ( $12 \%,<70$ years) (142, 143). In this review, the mean age at the time of ocular irAE diagnosis in patients with lung cancer was $66.84 \pm 10.36$ years. Based on the multivariate Cox regression analysis, the age was not an influencing factor for ocular irAEs $(\mathrm{p}=0.37)$. However, patients in pivotal clinical trials were commonly selected, particularly older patients with ICIs as are frailer $(144,145)$. In addition, there are limited reports on ocular irAEs in lung cancer, therefore necessitating further evaluation of the efficacy and safety of ICIs for older patients in a real-life setting (Figure 3 and Figure S1). Moreover, the onset time of ocular irAEs is not related to the age of patients with lung cancer.

\section{Gender}

Throughout the course of life, the incidence of malignancy is higher in men than women (146). However, cancer treatments in men have also demonstrated significantly better outcomes than those in women. Gender is a reportedly relevant element that modulates the expression of the PD-1 pathway (147). In addition, male patients demonstrate a better efficacy of single agent ICIs treatment than their female counterparts $(147,148)$. No studies have illustrated the difference in ICI-related irAEs between men and women $(146,149)$. Considering the 
vulnerability of women to autoimmune responses, the frequency of irAEs following ICIs might be more likely to occur in women than in men. In this review, females accounted for $39.13 \%$ of the patients with ocular irAEs in lung cancer. Moreover, we detected no significant gender difference among patients with ophthalmoplegia and other ocular irAEs, based on the multivariate Cox regression (Table 2, Figure 3, and Figure S1).

\section{Types of Tumor}

Different tumor types may cause different irAEs following ICIs. In a previous review involving 6938 patients with different tumor types, melanoma showed a higher incidence of gastrointestinal and skin irAE and lower incidence of pneumonitis after use of ICIs (132). In general, NSCLC represents $85 \%$ of all lung tumors, and the other $15 \%$ is SCLC $(150,151)$. In a review involving 14256 patients with lung cancer, it concluded that the incidence of ICI-related irAEs in individuals with NSCLC is less than with SCLC (21). While in this review, only three patients with SCLC suffered ocular irAEs. No studies with a large sample size of individuals focus on the ocular irAEs are reported and we cannot conclude the difference of the incidence of ocular irAEs between SCLC and NSCLC (21).

\section{MANAGEMENT STRATEGIES AND OUTCOMES FOR OCULAR irAES}

For the treatment of the ocular irAEs following ICIs, almost all cases of ocular irAEs were managed with conservative treatment, including topical or periocular corticosteroids. Symptomatic treatment is essential for controlling ocular irAEs, such as topical sodium hyaluronate for dry eye and cyclosporine for corneal perforation (152-154). Systemic treatment and suspension of ICIs were used in uncontrolled and serious cases, such as corneal graft rejection, corneal perforation. Based on the recommended guidelines of the ocular irAEs. The management and outcome of ophthalmoplegia, uveitis and dry eye had been described in detail as follows. Other ocular irAEs have been simply described clinical manifestation of ocular irAEs in part 3 .

\section{Management Strategies and Outcomes for Ophthalmoplegia}

Cholinesterase inhibitors (pyridostigmine) are the mainstay of therapy for ophthalmoplegia in MG. They are quick, safe, and free of long-term side effects (155). However, corticosteroids are required if cholinesterase inhibitors produce no response. A randomized controlled trial compared prednisone and placebo in patients with ocular MG who had previously failed to achieve minimal manifestation status, following 4 to 6 weeks of pyridostigmine use. Eighty-three percent of the patients under prednisone treatment acquired faster and better remission than those receiving placebo (156). Corticosteroids are widely available and cheap, and are the next step of treatment. They reportedly reduce the rate of generalization in patients with ptosis in MG (157). Low-dose corticosteroids might be more effective for ptosis in MG, and may decrease side effects with high-dose corticosteroids. Therapy with immunosuppressive and intravenous immunoglobulin or plasmapheresis have been found effective in a cohort of patients with MG $(93,94)$. It could also be used in patients treated with corticosteroids who were still symptomatic or had contraindications to corticosteroids, and experienced severe side effects with advanced systemic affections $(89,158)$. Suspending ICIs therapy is not necessary for the treatment of ophthalmoplegia in severe autoimmune $\mathrm{MG}$ (159). In this review, $84 \%$ of ocular irAEs in lung cancer followed by ICIs could acquire complete clinical recovery (Table 2 and Figure 4). The rate of ophthalmoplegia aggravation $(23.33 \%)$ was significantly higher than that of other ocular irAEs (7.69\%). In addition, the mortality of patients with ICI-related ophthalmoplegia was higher in lung cancer as well.

\section{Management Strategies and Outcomes for Uveitis}

Therapies for ICI-induced uveitis focus on controlling inflammation and decreasing the frequency of recurrence. Mydriasis prevents the formation of iris adhesions. Moreover, it can relieve photophobia from iris sphincter spasm and the pain of ciliary muscle action associated with iridocyclitis. Topical corticosteroids and systemic corticosteroids are the mainstays of treatment. The probability of uveitis relapse necessitates the maintenance of corticosteroids for patients who continue ICI therapy (160). Topical corticosteroids are usually effective in controlling inflammation in anterior uveitis. However, systemic corticosteroids are required for severe anterior uveitis, posterior uveitis, or panuveitis in lung cancer following ICI use (161). In addition, subconjunctival corticosteroids, intravitreal dexamethasone implant, and triamcinolone periocular space injection could also be effective. Uveitis detection might not be a sign to suspend ICI therapy, as the majority of ocular irAEs could acquire an excellent and rapid response to conventional treatment, with generally favorable clinical outcomes (28). In our review, all patients with uveitis in lung cancer following ICI use could be remised or acquired complete clinical recovery. Moreover, the average time of remission was $62.82 \pm 38.48$ days (Table 2 and Figure 4), consistent to previous studies $(28,32,88)$.

\section{Management Strategies and Outcomes for Dry Eye}

Preservative-free artificial tears are the mainstay of therapy for all severity grades of dry eye, which could increase tear film stability, improve contrast sensitivity and the optical quality of the surface. Autologous serum eyedrops could be useful and apply in in severe cases of dry eye. In addition, anti-inflammatory treatment should be conducted in moderate to severe cases with dry eye. Topical corticosteroid eyedrops for 2 to 4 weeks had been reported symptomatic improvement in a randomized and double-masked study (162). Cyclosporine A could increase the production of tear fluid, and had been reported to reduce symptoms, improve the Schirmer test values in previous studies $(109,111,163)$. It had been 


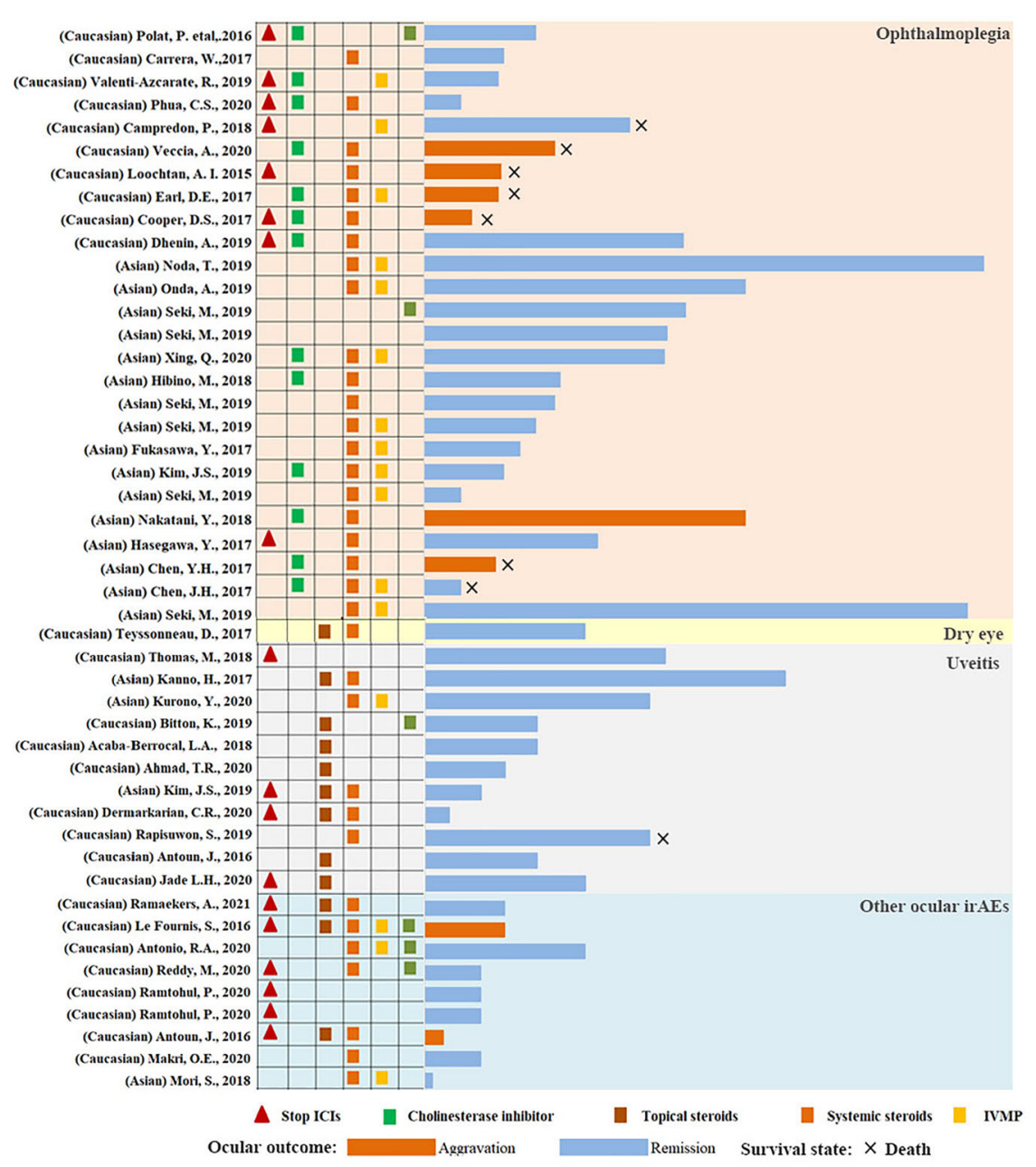

FIGURE 4 | The course of the ocular irAEs following ICl use in lung cancer. The column indicates the length of the complication in each patient with ocular irAEs. Light pink, light gray, light yellow, and light blue represent ophthalmoplegia, uveitis, dry eye, and other ocular irAEs. The blue column represents remission or complete recovery. The dark yellow column represents an aggravation of disease or death.

approved by FDA for treatment of dry eye. However, systemic corticosteroid, immunosuppression or suspension of ICIs are not recommended for dry eye (109).

\section{LIMITATIONS}

There are several limitations in this review. At first, the sample size is limited. Only 79 patients with ocular irAEs in lung cancer had been searched. Most of the recruited cases are from case report or case series, we cannot deduce the accurate incidence of the ocular irAEs in lung cancer following ICIs. Moreover, some ocular irAEs with a lower frequency might not be reported. Secondly, most of studies were focused on the systemic irAEs not the ocular irAEs and the detailed clinical characteristics of the ocular irAEs are not available. The treatment of the ocular irAEs in different studies were not identical as well, including the initiation time and dose of the drugs, the types of drugs, following time and so on. We do not summarize the detailed features and treatment of each ocular irAEs based on the recruited studies.

\section{CONCLUSIONS}

ICIs have greatly changed the prognosis of lung cancer, which was previously considered as a fatal tumor. With the widespread use of ICIs, more and more related toxicities have been reported. Although ocular irAEs are infrequent based on the previous study, they can cause a deterioration of the quality of life and exert an influence on the compliance of patients. Lots of studies have reported the ocular adverse events secondary to ICIs (19, $25,26,30,31,153,164-168)$ and the grade of the adverse events had been published recently based on Common Terminology Criteria for Adverse Events. While no study had reported the ocular irAEs in lung cancer. Previously, dry eye and uveitis were 
the most common ocular irAEs. However, ophthalmoplegia especially ptosis, has been considered as the most common reported irAEs in lung cancer in this study.

All of the patients with ophthalmoplegia secondary to ICIs are the complication of myasthenia gravis in this study. While the most fatal manifestations including respiratory depression and myocarditis can be detected in approximately two-thirds of individuals with myasthenia gravis. The high incidence of ophthalmoplegia with myasthenia gravis in ocular irAEs and the high mortality of life-threatening myasthenia gravis in lung cancer necessitate an increase in ophthalmoplegia vigilance. This reminds us of timely identification of the ophthalmoplegia with myasthenia gravis, particularly in the early stages of irAEs. Based on this study, we found that the prevalence of ophthalmoplegia in Asian, the combination therapy of PD-L1+CTLA4 inhibitors were significantly higher than uveitis or other ocular irAEs. Preexiting autoimmune diseases could cause a higher incidence of the ocular irAEs in lung cancer. The onset time of the ophthalmoplegia is earlier than other ocular irAEs (within 10 weeks after initiation of ICIs). This could help us to easily diagnose and identify the ocular irAEs, especially for ophthalmoplegia.

Due to the sample size of ocular irAEs in lung cancer is limited and most of the recruited patients were come from case reports, further additionally studies on ocular irAEs were urgently needed to illustrate the ICI-related ocular irAEs. The understanding of ocular irAEs is necessary to guide the proper prevention and treatment plan and improve the quality of life of patients. Open communication between internist, oncologist and

\section{REFERENCES}

1. Cai Z, Xu D, Zhang Q, Zhang J, Ngai SM, Shao J. Classification of Lung Cancer Using Ensemble-Based Feature Selection and Machine Learning Methods. Mol Biosyst (2015) 11:791-800. doi: 10.1039/c4mb00659c

2. Bade BC, Dela Cruz CS. Lung Cancer 2020: Epidemiology, Etiology, and Prevention. Clin Chest Med (2020) 41:1-24. doi: 10.1016/j.ccm. 2019.10.001

3. Bray F, Ferlay J, Soerjomataram I, Siegel RL, Torre LA, Jemal A. Global Cancer Statistics 2018: GLOBOCAN Estimates of Incidence and Mortality Worldwide for 36 Cancers in 185 Countries. CA Cancer J Clin (2018) 68:394-424. doi: 10.3322/caac.21492

4. Suresh K, Naidoo J, Lin CT, Danoff S. Immune Checkpoint Immunotherapy for Non-Small Cell Lung Cancer: Benefits and Pulmonary Toxicities. Chest (2018) 154:1416-23. doi: 10.1016/j.chest.2018.08.1048

5. Bodor JN, Boumber Y, Borghaei H. Biomarkers for Immune Checkpoint Inhibition in Non-Small Cell Lung Cancer (NSCLC). Cancer (2020) 126:260-70. doi: 10.1002/cncr.32468

6. Khan M, Lin J, Liao G, Tian Y, Liang Y, Li R, et al. Comparative Analysis of Immune Checkpoint Inhibitors and Chemotherapy in the Treatment of Advanced Non-Small Cell Lung Cancer: A Meta-Analysis of Randomized Controlled Trials. Med (Baltimore) (2018) 97:e11936. doi: 10.1097/ MD.0000000000011936

7. Apetoh L, Ladoire S, Coukos G, Ghiringhelli F. Combining Immunotherapy and Anticancer Agents: The Right Path to Achieve Cancer Cure? Ann Oncol (2015) 26:1813-23. doi: 10.1093/anNonc/mdv209

8. Bodor JN, Kasireddy V, Borghaei H. First-Line Therapies for Metastatic Lung Adenocarcinoma Without a Driver Mutation. J Oncol Pract (2018) 14:529-35. doi: 10.1200/JOP.18.00250

9. Motzer RJ, Escudier B, George S, Hammers HJ, Srinivas S, Tykodi SS, et al. Nivolumab Versus Everolimus in Patients With Advanced Renal Cell Carcinoma: Updated Results With Long-Term Follow-Up of the ophthalmologists is necessary to identify and manage the ocular irAEs.

\section{AUTHOR CONTRIBUTIONS}

LZ searched the literature and wrote the manuscript and conducted the statistics analysis. XW revised the manuscript, and verified the study. All authors contributed to the article and approved the submitted version.

\section{FUNDING}

Supported by grants from the Natural Science Foundation of China (No. 82070954); The Applied Basic Research Programs of Science and Technology Commission Foundation of Sichuan Province (No. 19YYJC0790); The Innovative Spark Grant of Sichuan University (No. 2018SCUH0062).

\section{SUPPLEMENTARY MATERIAL}

The Supplementary Material for this article can be found online at: https://www.frontiersin.org/articles/10.3389/fimmu.2021. 701951/full\#supplementary-material

Randomized, Open-Label, Phase 3 CheckMate 025 Trial. Cancer (2020) 126:4156-67. doi: 10.1002/cncr.33033

10. Motzer RJ, Escudier B, McDermott DF, George S, Hammers HJ, Srinivas S, et al. Nivolumab Versus Everolimus in Advanced Renal-Cell Carcinoma. N Engl J Med (2015) 373:1803-13. doi: 10.1056/NEJMoa1510665

11. Lai LT, Zhan ZY, Feng M, Li F, Lai LF, Zhong LX. Immune Checkpoint Inhibitors for the Management of Advanced Non-Small-Cell Lung Carcinoma: A Meta-Analysis. Anticancer Drugs (2020) 31:637-45. doi: 10.1097/CAD.0000000000000921

12. Yoneda K, Imanishi N, Ichiki Y, Tanaka F. Immune Checkpoint Inhibitors (ICIs) in Non-Small Cell Lung Cancer (NSCLC). J UOEH (2018) 40:173-89. doi: 10.7888 /juoeh.40.173

13. Morgensztern D, Herbst RS. Nivolumab and Pembrolizumab for Non-Small Cell Lung Cancer. Clin Cancer Res (2016) 22:3713-7. doi: 10.1158/10780432.CCR-15-2998

14. Postow MA, Sidlow R, Hellmann MD. Immune-Related Adverse Events Associated With Immune Checkpoint Blockade. N Engl J Med (2018) 378:158-68. doi: 10.1056/NEJMra1703481

15. La-Beck NM, Jean GW, Huynh C, Alzghari SK, Lowe DB. Immune Checkpoint Inhibitors: New Insights and Current Place in Cancer Therapy. Pharmacotherapy (2015) 35:963-76. doi: 10.1002/phar.1643

16. Mazarico Gallego JM, Herrera Juarez M, Paz-Ares L. The Safety and Efficacy of Pembrolizumab for the Treatment of Non-Small Cell Lung Cancer. Expert Opin Drug Saf (2020) 19:233-42. doi: 10.1080/14740338.2020.1736554

17. Ramos-Casals M, Brahmer JR, Callahan MK, Flores-Chavez A, Keegan N, Khamashta MA, et al. Immune-Related Adverse Events of Checkpoint Inhibitors. Nat Rev Dis Primers (2020) 6:38. doi: 10.1038/s41572-0200160-6

18. Davies M, Duffield EA. Safety of Checkpoint Inhibitors for Cancer Treatment: Strategies for Patient Monitoring and Management of Immune-Mediated Adverse Events. Immunotargets Ther (2017) 6:51-71. doi: 10.2147/ITT.S141577 
19. Dalvin LA, Shields CL, Orloff M, Sato T, Shields JA. CHECKPOINT INHIBITOR IMMUNE THERAPY: Systemic Indications and Ophthalmic Side Effects. Retina (2018) 38:1063-78. doi: 10.1097/IAE.0000000000002181

20. Weber JS, Yang JC, Atkins MB, Disis ML. Toxicities of Immunotherapy for the Practitioner. J Clin Oncol (2015) 33:2092-9. doi: 10.1200/ JCO.2014.60.0379

21. Shao J, Wang C, Ren P, Jiang Y, Tian P, Li W. Treatment- and ImmuneRelated Adverse Events of Immune Checkpoint Inhibitors in Advanced Lung Cancer. Biosci Rep (2020) 40:BSR20192347. doi: 10.1042/BSR20192347

22. Ferrari SM, Fallahi P, Elia G, Ragusa F, Ruffilli I, Patrizio A, et al. Autoimmune Endocrine Dysfunctions Associated With Cancer Immunotherapies. Int J Mol Sci (2019) 20:2560. doi: 10.3390/ijms20102560

23. Ma K, Lu Y, Jiang S, Tang J, Li X, Zhang Y. The Relative Risk and Incidence of Immune Checkpoint Inhibitors Related Pneumonitis in Patients With Advanced Cancer: A Meta-Analysis. Front Pharmacol (2018) 9:1430. doi: 10.3389/fphar.2018.01430

24. Ramos-Casals M, Maria A, Suarez-Almazor ME, Lambotte O, Fisher BA, Hernandez-Molina G, et al. Sicca/Sjogren's Syndrome Triggered by PD-1/ PD-L1 Checkpoint Inhibitors. Data From the International ImmunoCancer Registry (ICIR). Clin Exp Rheumatol (2019) 37:114-22.

25. Sun MM, Seleme N, Chen JJ, Zekeridou A, Sechi E, Walsh RD, et al. NeuroOphthalmic Complications in Patients Treated With CTLA-4 and PD-1/ PD-L1 Checkpoint Blockade. J Neuroophthalmol (2020). doi: 10.1097/ WNO.0000000000001148

26. Bomze D, Meirson T, Hasan Ali O, Goldman A, Flatz L, Habot-Wilner Z. Ocular Adverse Events Induced by Immune Checkpoint Inhibitors: A Comprehensive Pharmacovigilance Analysis. Ocul Immunol Inflammation (2020) 1-7. doi: 10.1080/09273948.2020.1773867

27. Abdel-Wahab N, Shah M, Suarez-Almazor ME. Adverse Events Associated With Immune Checkpoint Blockade in Patients With Cancer: A Systematic Review of Case Reports. PloS One (2016) 11:e0160221. doi: 10.1371/ journal.pone.0160221

28. Sun Mm M.D PD, Levinson RMD, Filipowicz ADO, Anesi SMD, Kaplan HMD, P.D. Wang WMD, et al. Uveitis in Patients Treated With CTLA-4 and PD-1 Checkpoint Blockade Inhibition. Ocul Immunol Inflamm (2020) 28:217-27. doi: 10.1080/09273948.2019.1577978

29. Bitton K, Michot JM, Barreau E, Lambotte O, Haigh O, Marabelle A, et al. Prevalence and Clinical Patterns of Ocular Complications Associated With Anti-PD-1/PD-L1 Anticancer Immunotherapy. Am J Ophthalmol (2019) 202:109-17. doi: 10.1016/j.ajo.2019.02.012

30. Sun MM, Kelly SP, Mylavarapu Bs AL, Holland GN, Coleman AL, Yu F, et al. Ophthalmic Immune-Related Adverse Events After Anti-CTLA-4 or PD-1 Therapy Recorded in the American Academy of Ophthalmology Intelligent Research in Sight Registry. Ophthalmology (2020) 128:910-9. doi: 10.1016/j.ophtha.2020.11.001

31. Fortes BH, Liou H, Dalvin LA. Ophthalmic Adverse Effects of Immune Checkpoint Inhibitors: The Mayo Clinic Experience. Br J Ophthalmol (2020) 0:1-9. doi: 10.1136/bjophthalmol-2020-316970

32. Park RB, Jain S, Han H, Park J. Ocular Surface Disease Associated With Immune Checkpoint Inhibitor Therapy. Ocul Surf (2021) 20:115-29. doi: 10.1016/j.jtos.2021.02.004

33. Makri OE, Dimitrakopoulos FI, Tsapardoni F, Tsekouras I, Argyriou AA, Kalofonos H, et al. Isolated Optic Neuritis After Pembrolizumab Administration for Non-Small-Cell Lung Carcinoma. Int J Neurosci (2020) 1-6. doi: 10.1080/00207454.2020.1831489

34. Hasegawa Y, Kawai S, Ota T, Tsukuda H, Fukuoka M. Myasthenia Gravis Induced by Nivolumab in Patients With Non-Small-Cell Lung Cancer: A Case Report and Literature Review. Immunotherapy (2017) 9:701-7. doi: 10.2217/imt-2017-0043

35. Polat $\mathrm{P}$, Donofrio PD. Myasthenia Gravis Induced by Nivolumab Therapy in a Patient With Non-Small-Cell Lung Cancer. Muscle Nerve (2016) 54:507. doi: $10.1002 /$ mus. 25163

36. Loochtan AI, Nickolich MS, Hobson-Webb LD. Myasthenia Gravis Associated With Ipilimumab and Nivolumab in the Treatment of Small Cell Lung Cancer. Muscle Nerve (2015) 52:307-8. doi: 10.1002/mus.24648

37. Chen JH, Lee KY, Hu CJ, Chung CC. Coexisting Myasthenia Gravis, Myositis, and Polyneuropathy Induced by Ipilimumab and Nivolumab in a Patient With Non-Small-Cell Lung Cancer: A Case Report and
Literature Review. Med (Baltimore) (2017) 96:e9262. doi: 10.1097/MD. 0000000000009262

38. Reyes-Bueno JA, Rodriguez-Santos L, Serrano-Castro PJ. Myasthenia Gravis Induced by Inmuno Checkpoints Inhibitors: First Case Report Secondary to Avelumab Therapy and Review of Published Cases. Rev Neurol (2019) 68:333-8. doi: 10.33588/rn.6808.2018497

39. Carrera W, Baartman BJ, Kosmorsky G. A Case Report of Drug-Induced Myopathy Involving Extraocular Muscles After Combination Therapy With Tremelimumab and Durvalumab for Non-Small Cell Lung Cancer. Neuroophthalmology (2017) 41:140-3. doi: 10.1080/01658107.2017.1291686

40. Brahmer JR, Lacchetti C, Thompson JA. Management of Immune-Related Adverse Events in Patients Treated With Immune Checkpoint Inhibitor Therapy: American Society of Clinical Oncology Clinical Practice Guideline Summary. J Oncol Pract (2018) 14:247-9. doi: 10.1200/JOP.18.00005

41. Le Fournis S, Gohier P, Urban T, Jeanfaivre T, Hureaux J. Corneal Graft Rejection in a Patient Treated With Nivolumab for Primary Lung Cancer. Lung Cancer (2016) 102:28-9. doi: 10.1016/j.lungcan.2016.10.008

42. Reddy M, Chen JJ, Kalevar A, Terribilini R, Agarwal A. Immune Retinopathy Associated With Nivolumab Administration for Metastatic Non-Small Cell Lung Cancer. Retin cases Brief Rep (2020) 14:120-6. doi: 10.1097/ICB.0000000000000675

43. Ahmad TR, Doan T, Gonzales JA, Acharya NR, Tsui E. Clinical Course of Preexisting Uveitis During Treatment of Lung Cancer With Durvalumab. Ocul Immunol Inflamm (2020) 28:566-70. doi: 10.1080/09273948. 2019.1678652

44. Antoun J, Titah C, Cochereau I. Ocular and Orbital Side-Effects of Checkpoint Inhibitors: A Review Article. Curr Opin Oncol (2016) 28:28894. doi: $10.1097 / C C O .0000000000000296$

45. Kanno H, Ishida K, Yamada W, Nishida T, Takahashi N, Mochizuki K, et al. Uveitis Induced by Programmed Cell Death Protein 1 Inhibitor Therapy With Nivolumab in Metastatic Melanoma Patient. J Infect Chemother (2017) 23:774-7. doi: 10.1016/j.jiac.2017.04.007

46. Seki M, Uruha A, Ohnuki Y, Kamada S, Noda T, Onda A, et al. Inflammatory Myopathy Associated With PD-1 Inhibitors. J Autoimmun (2019) 100:105-13. doi: 10.1016/j.jaut.2019.03.005

47. Kim JS, Nam TS, Kim J, Kho BG, Park CK, Oh IJ, et al. Myasthenia Gravis and Myopathy After Nivolumab Treatment for Non-Small Cell Lung Carcinoma: A Case Report. Thorac Cancer (2019) 10:2045-9. doi: 10.1111/ 1759-7714.13177

48. Felip E, de Braud FG, Maur M, Loong HH, Shaw AT, Vansteenkiste JF, et al. Ceritinib Plus Nivolumab in Patients With Advanced ALK-Rearranged NonSmall Cell Lung Cancer: Results of an Open-Label, Multicenter, Phase 1b Study. J Thorac Oncol (2020) 15:392-403. doi: 10.1016/j.jtho.2019.10.006

49. Chen YH, Liu FC, Hsu CH, Chian CF. Nivolumab-Induced Myasthenia Gravis in a Patient With Squamous Cell Lung Carcinoma: Case Report. Med (Baltimore) (2017) 96:e7350. doi: 10.1097/MD.0000000000007350

50. Nakatani $Y$, Tanaka N, Enami T, Minami S, Okazaki T, Komuta K. LambertEaton Myasthenic Syndrome Caused by Nivolumab in a Patient With Squamous Cell Lung Cancer. Case Rep Neurol (2018) 10:346-52. doi: $10.1159 / 000494078$

51. Veccia A, Kinspergher S, Grego E, Peterlana D, Berti A, Tranquillini E, et al. Myositis and Myasthenia During Nivolumab Administration for Advanced Lung Cancer: A Case Report and Review of the Literature. Anticancer Drugs (2020) 31:540-4. doi: 10.1097/CAD.0000000000000903

52. Reck M, Rodriguez-Abreu D, Robinson AG, Hui R, Csoszi T, Fulop A, et al. Updated Analysis of KEYNOTE-024: Pembrolizumab Versus PlatinumBased Chemotherapy for Advanced Non-Small-Cell Lung Cancer With PD-L1 Tumor Proportion Score of 50\% or Greater. J Clin Oncol (2019) 37:537-46. doi: 10.1200/JCO.18.00149

53. Gadgeel SM, Stevenson JP, Langer CJ, Gandhi L, Borghaei H, Patnaik A, et al. Pembrolizumab and Platinum-Based Chemotherapy as First-Line Therapy for Advanced Non-Small-Cell Lung Cancer: Phase 1 Cohorts From the KEYNOTE-021 Study. Lung Cancer (2018) 125:273-81. doi: 10.1016/j.lungcan.2018.08.019

54. Satouchi M, Nosaki K, Takahashi T, Nakagawa K, Aoe K, Kurata T, et al. First-Line Pembrolizumab vs Chemotherapy in Metastatic Non-Small-Cell Lung Cancer: KEYNOTE-024 Japan Subset. Cancer Sci (2020) 111:4480-9. doi: $10.1111 /$ cas. 14647 
55. Noda T, Kageyama H, Miura M, Tamura T, Ito H. A Case of Myasthenia Gravis and Myositis Induced by Pembrolizumab. Rinsho Shinkeigaku (2019) 59:502-8. doi: 10.5692/clinicalneurol.cn-001251

56. Ma Y, Fang W, Zhang Y, Yang Y, Hong S, Zhao Y, et al. KEYNOTE-032: A Randomized Phase I Study of Pembrolizumab in Chinese Patients With Advanced Non-Small Cell Lung Cancer. Oncologist (2020) 25:650-e1145. doi: 10.1634/theoncologist.2020-0067

57. Onda A, Miyagawa S, Takahashi N, Gochi M, Takagi M, Nishino I, et al. Pembrolizumab-Induced Ocular Myasthenia Gravis With Anti-Titin Antibody and Necrotizing Myopathy. Intern Med (2019) 58:1635-8. doi: 10.2169/internalmedicine.1956-18

58. Kurono Y, Takeda T, Kunimatsu Y, Tani N, Hashimoto I, Hirose K. VogtKoyanagi-Harada Disease During Chemoimmunotherapy for Non-Small Cell Lung Cancer. Respirol Case Rep (2020) 8:e00545. doi: 10.1002/rcr2.545

59. Razak AR, Cleary JM, Moreno V, Boyer M, Calvo Aller E, Edenfield W, et al. Safety and Efficacy of AMG 820, an Anti-Colony-Stimulating Factor 1 Receptor Antibody, in Combination With Pembrolizumab in Adults With Advanced Solid Tumors. J Immunother Cancer (2020) 8:e001006. doi: 10.1136/jitc-2020-001006

60. Hibino M, Maeda K, Horiuchi S, Fukuda M, Kondo T. PembrolizumabInduced Myasthenia Gravis With Myositis in a Patient With Lung Cancer. Respirol Case Rep (2018) 6:e00355. doi: 10.1002/rcr2.355

61. Acaba-Berrocal LA, Lucio-Alvarez JA, Mashayekhi A, Ho AC, Dunn JP, Shields CL. Birdshot-Like Chorioretinopathy Associated With Pembrolizumab Treatment. JAMA Ophthalmol (2018) 136:1205-7. doi: 10.1001/jamaophthalmol.2018.1851

62. Ramaekers A, Aspeslagh S, De Brucker N, Van Mierlo C, Ten Tusscher M, Schauwvlieghe PP, et al. Bilateral Corneal Perforation in a Patient Under AntiPD1 Therapy. Cornea (2021) 40:245-7. doi: 10.1097/ICO.0000000000002490

63. Tamura T, Akimoto E, Matsumoto C, Mori S, Nishi T, Kudo K, et al. VogtKoyanagi-Harada Syndrome Induced by Pembrolizumab in a Patient With Non-Small Cell Lung Cancer. J Thorac Oncol (2018) 13:1606-7. doi: 10.1016/j.jtho.2018.04.026

64. Lara MS, Afify A, Ellis MP, Phan CT, Richman DP, Riess JW. Immune Checkpoint Inhibitor-Induced Myasthenia Gravis in a Patient With Advanced NSCLC and Remote History of Thymoma. Clin Lung Cancer (2019) 20:e489-91. doi: 10.1016/j.cllc.2019.04.007

65. Micaily I, Chernoff M. An Unknown Reaction to Pembrolizumab: Giant Cell Arteritis. Ann Oncol (2017) 28:2621-2. doi: 10.1093/anNonc/mdx306

66. Ramtohul P, Freund KB. Clinical and Morphological Characteristics of AntiProgrammed Death Ligand 1-Associated Retinopathy: Expanding the Spectrum of Acute Macular Neuroretinopathy. Ophthalmol Retina (2020) 4:446-50. doi: 10.1016/j.oret.2019.11.006

67. Gulley JL, Rajan A, Spigel DR, Iannotti N, Chandler J, Wong DJL, et al. Avelumab for Patients With Previously Treated Metastatic or Recurrent Non-Small-Cell Lung Cancer (JAVELIN Solid Tumor): Dose-Expansion Cohort of a Multicentre, Open-Label, Phase 1b Trial. Lancet Oncol (2017) 18:599-610. doi: 10.1016/S1470-2045(17)30240-1

68. Sabini E, Sframeli A, Marino M. A Case of Drug-Induced Graves' Orbitopathy After Combination Therapy With Tremelimumab and Durvalumab. J Endocrinol Invest (2018) 41:877-8. doi: 10.1007/s40618-018-0906-0

69. Antonia SJ, Lopez-Martin JA, Bendell J, Ott PA, Taylor M, Eder JP, et al. Nivolumab Alone and Nivolumab Plus Ipilimumab in Recurrent Small-Cell Lung Cancer (CheckMate 032): A Multicentre, Open-Label, Phase 1/2 Trial. Lancet Oncol (2016) 17:883-95. doi: 10.1016/S1470-2045(16)30098-5

70. Phua CS, Murad A, Fraser C, Bray V, Cappelen-Smith C. Myasthenia Gravis and Concurrent Myositis Following PD-L1 Checkpoint Inhibitor for NonSmall Cell Lung Cancer. BMJ Neurol Open (2020) 2:e000028. doi: 10.1136/ bmjno-2019-000028

71. Xing Q, Zhang ZW, Lin QH, Shen LH, Wang PM, Zhang S, et al. MyositisMyasthenia Gravis Overlap Syndrome Complicated With Myasthenia Crisis and Myocarditis Associated With Anti-Programmed Cell Death-1 (Sintilimab) Therapy for Lung Adenocarcinoma. Ann Transl Med (2020) 8:250. doi: $10.21037 /$ atm.2020.01.79

72. Kamo H, Hatano T, Kanai K, Aoki N, Kamiyama D, Yokoyama K, et al. Pembrolizumab-Related Systemic Myositis Involving Ocular and Hindneck Muscles Resembling Myasthenic Gravis: A Case Report. BMC Neurol (2019) 19:184. doi: 10.1186/s12883-019-1416-1
73. Dhenin A, Samartzi V, Lejeune S, Seront E. Cascade of Immunologic Adverse Events Related to Pembrolizumab Treatment. BMJ Case Rep (2019) 12:e229149. doi: 10.1136/bcr-2018-229149

74. Cooper DS, Meriggioli MN, Bonomi PD, Malik R. Severe Exacerbation of Myasthenia Gravis Associated With Checkpoint Inhibitor Immunotherapy. J Neuromuscul Dis (2017) 4:169-73. doi: 10.3233/JND-170219

75. Valenti-Azcarate R, Esparragosa Vazquez I, Toledano Illan C, Idoate Gastearena MA, Gallego Perez-Larraya J. Nivolumab and IpilimumabInduced Myositis and Myocarditis Mimicking a Myasthenia Gravis Presentation. Neuromuscul Disord (2020) 30:67-9. doi: 10.1016/ j.nmd.2019.10.006

76. Earl DE, Loochtan AI, Bedlack RS. Refractory Myasthenia Gravis Exacerbation Triggered By Pembrolizumab. Muscle Nerve (2018) 57: E120-1. doi: 10.1002/mus.26021

77. Deitch-Harel IM, Raskin EM, Habot-Wilner ZM, Friling RM, Amer RM, Kramer MM. Uveitis Induced by Biological Agents Used in Cancer Therapy. Ocul Immunol Inflammation (2020) 1-5. doi: 10.1080/09273948.2020.1760310

78. Rapisuwon S, Izar B, Batenchuk C, Avila A, Mei S, Sorger P, et al. Exceptional Response and Multisystem Autoimmune-Like Toxicities Associated With the Same T Cell Clone in a Patient With Uveal Melanoma Treated With Immune Checkpoint Inhibitors. J Immunother Cancer (2019) 7:61. doi: 10.1186/s40425-019-0533-0

79. Campredon P, Imbert P, Mouly C, Grunenwald S, Mazieres J, Caron P. Severe Inflammatory Ophthalmopathy in a Euthyroid Patient During Nivolumab Treatment. Eur Thyroid J (2018) 7:84-7. doi: 10.1159/000485742

80. Thomas M, Armenti ST, Ayres MB, Demirci H. Uveal Effusion After Immune Checkpoint Inhibitor Therapy. JAMA Ophthalmol (2018) 136:553-6. doi: 10.1001/jamaophthalmol.2018.0920

81. Fukasawa Y, Sasaki K, Natsume M, Nakashima M, Ota S, Watanabe K, et al. Nivolumab-Induced Myocarditis Concomitant With Myasthenia Gravis. Case Rep Oncol (2017) 10:809-12. doi: 10.1159/000479958

82. Mori S, Kurimoto T, Ueda K, Enomoto H, Sakamoto M, Keshi Y, et al. Optic Neuritis Possibly Induced by Anti-PD-L1 Antibody Treatment in a Patient With Non-Small Cell Lung Carcinoma. Case Rep Ophthalmol (2018) 9:34856. doi: 10.1159/000491075

83. Horisberger A, La Rosa S, Zurcher JP, Zimmermann S, Spertini F, Coukos G, et al. A Severe Case of Refractory Esophageal Stenosis Induced by Nivolumab and Responding to Tocilizumab Therapy. J Immunother Cancer (2018) 6:156. doi: 10.1186/s40425-018-0481-0

84. Teyssonneau D, Cousin S, Italiano A. Gougerot-Sjogren-Like Syndrome Under PD-1 Inhibitor Treatment. Ann Oncol (2017) 28:3108. doi: 10.1093/ anNonc/mdx 531

85. J LH, L MB, El Rahi C, A CS, Bernicker EH. Panuveitis in Patient on Ipilimumab/Nivolumab Combination for Small-Cell Lung Cancer Treated With an Intravitreal Dexamethasone Implant. J Oncol Pharm Pract (2020) 27:1078155220969792. doi: 10.1177/1078155220969792

86. A RA, Moll-Udina A, Martin R, Cilveti E, Subira O, Disfetano L, et al. Retinal Vasculitis Secondary to Durvalumab. Case Rep Ophthalmol (2020) 11:161-6. doi: $10.1159 / 000507609$

87. Dermarkarian CR, Patel NA, Villegas VM, Harbour JW. Bilateral Uveitis Associated With Nivolumab Therapy for Metastatic Non-Small Cell Lung Cancer. Am J Ophthalmol (2020) 18:100691. doi: 10.1016/j.ajoc.2020.100691

88. Dow ER, Yung M, Tsui E. Immune Checkpoint Inhibitor-Associated Uveitis: Review of Treatments and Outcomes. Ocul Immunol Inflamm (2021) 29:203-11. doi: 10.1080/09273948.2020.1781902

89. Su C, Wang H, Liu Y, Guo Q, Zhang L, Li J, et al. Adverse Effects of Anti-PD1/PD-L1 Therapy in Non-Small Cell Lung Cancer. Front Oncol (2020) 10:554313. doi: 10.3389/fonc.2020.554313

90. Wang DY, Salem JE, Cohen JV, Chandra S, Menzer C, Ye F, et al. Fatal Toxic Effects Associated With Immune Checkpoint Inhibitors: A Systematic Review and Meta-Analysis. JAMA Oncol (2018) 4:1721-8. doi: 10.1001/ jamaoncol.2018.3923

91. Mancone S, Lycan T, Ahmed T, Topaloglu U, Dothard A, Petty WJ, et al. Severe Neurologic Complications of Immune Checkpoint Inhibitors: A Single-Center Review. J Neurol (2018) 265:1636-42. doi: 10.1007/s00415-018-8890-z

92. Diaz-Manera J, Luna S, Roig C. Ocular Ptosis: Differential Diagnosis and Treatment. Curr Opin Neurol (2018) 31:618-27. doi: 10.1097/WCO. 0000000000000600 
93. Safa H, Johnson DH, Trinh VA, Rodgers TE, Lin H, Suarez-Almazor ME, et al. Immune Checkpoint Inhibitor Related Myasthenia Gravis: Single Center Experience and Systematic Review of the Literature. J Immunother Cancer (2019) 7:319. doi: 10.1186/s40425-019-0774-y

94. Europa TA, Nel M, Heckmann JM. Myasthenic Ophthalmoparesis: Time To Resolution After Initiating Immune Therapies. Muscle Nerve (2018) 58:5429. doi: 10.1002/mus.26172

95. Narayanaswami P, Sanders DB, Wolfe G, Benatar M, Cea G, Evoli A, et al. International Consensus Guidance for Management of Myasthenia Gravis: 2020 Update. Neurology (2021) 96:114-22. doi: 10.1212/WNL.0000000000011124

96. Melson AT, McClelland CM, Lee MS. Ocular Myasthenia Gravis: Updates on an Elusive Target. Curr Opin Neurol (2020) 33:55-61. doi: 10.1097/ WCO. 0000000000000775

97. Moslehi JJ, Salem JE, Sosman JA, Lebrun-Vignes B, Johnson DB. Increased Reporting of Fatal Immune Checkpoint Inhibitor-Associated Myocarditis. Lancet (2018) 391:933. doi: 10.1016/S0140-6736(18)30533-6

98. Mier A, Laroche C, Green M. Unsuspected Myasthenia Gravis Presenting as Respiratory Failure. Thorax (1990) 45:422-3. doi: 10.1136/thx.45.5.422

99. Choi J, Lee SY. Clinical Characteristics and Treatment of Immune-Related Adverse Events of Immune Checkpoint Inhibitors. Immune Netw (2020) 20 : e9. doi: 10.4110/in.2020.20.e9

100. Becquart O, Lacotte J, Malissart P, Nadal J, Lesage C, Guillot B, et al. Myasthenia Gravis Induced by Immune Checkpoint Inhibitors. J Immunother (2019) 42:309-12. doi: 10.1097/CJI.0000000000000278

101. Smith SV, Lee AG. Update on Ocular Myasthenia Gravis. Neurol Clin (2017) 35:115-23. doi: 10.1016/j.ncl.2016.08.008

102. Fortin E, Cestari DM, Weinberg DH. Ocular Myasthenia Gravis: An Update on Diagnosis and Treatment. Curr Opin Ophthalmol (2018) 29:477-84. doi: 10.1097/ICU.0000000000000526

103. Gilhus NE, Tzartos S, Evoli A, Palace J, Burns TM, Verschuuren J. Myasthenia Gravis. Nat Rev Dis Primers (2019) 5:30. doi: 10.1038/s41572-019-0079-y

104. Pasnoor M, Dimachkie MM, Farmakidis C, Barohn RJ. Diagnosis of Myasthenia Gravis. Neurol Clin (2018) 36:261-74. doi: 10.1016/j.ncl.2018.01.010

105. Krishna U, Ajanaku D, Denniston AK, Gkika T. Uveitis: A SightThreatening Disease Which can Impact All Systems. Postgrad Med J (2017) 93:766-73. doi: 10.1136/postgradmedj-2017-134891

106. Rouen PA, White ML. Dry Eye Disease: Prevalence, Assessment, and Management. Home Healthc Now (2018) 36:74-83. doi: 10.1097/NHH. 0000000000000652

107. Messmer EM. The Pathophysiology, Diagnosis, and Treatment of Dry Eye Disease. Dtsch Arztebl Int (2015) 112:71-81. doi: 10.3238/arztebl.2015.0071

108. Lemp MA, Crews LA, Bron AJ, Foulks GN, Sullivan BD. Distribution of Aqueous-Deficient and Evaporative Dry Eye in a Clinic-Based Patient Cohort: A Retrospective Study. Cornea (2012) 31:472-8. doi: 10.1097/ ICO.0b013e318225415a

109. Sumida T, Azuma N, Moriyama M, Takahashi H, Asashima H, Honda F, et al. Clinical Practice Guideline for Sjogren's Syndrome 2017. Mod Rheumatol (2018) 28:383-408. doi: 10.1080/14397595.2018.1438093

110. Lemp MA, Baudouin C, Baum J, Dogru M, Foulks GN, Kinoshita S, et al The Definition and Classification of Dry Eye Disease: Report of the Definition and Classification Subcommittee of the International Dry Eye WorkSho). Ocul Surf (2007) 5:75-92. doi: 10.1016/s1542-0124(12)70081-2

111. Nelson JD, Craig JP, Akpek EK, Azar DT, Belmonte C, Bron AJ, et al. TFOS DEWS II Introduction. Ocul Surf (2017) 15:269-75. doi: 10.1016/j.jtos. 2017.05.005

112. Stamate AC, Tataru CP, Zemba M. Update on Surgical Management of Corneal Ulceration and Perforation. Rom J Ophthalmol (2019) 63:166-73. doi: $10.22336 /$ rjo.2019.25

113. Deshmukh R, Stevenson LJ, Vajpayee R. Management of Corneal Perforations: An Update. Indian J Ophthalmol (2020) 68:7-14. doi: 10.4103/ijoIJO_1151_19

114. Panda A, Vanathi M, Kumar A, Dash Y, Priya S. Corneal Graft Rejection. Surv Ophthalmol (2007) 52:375-96. doi: 10.1016/j.survophthal.2007.04.008

115. Yin J. Advances in Corneal Graft Rejection. Curr Opin Ophthalmol (2021) 32:331-7. doi: 10.1097/ICU.0000000000000767

116. Dutta Majumder P, Marchese A, Pichi F, Garg I, Agarwal A. An Update on Autoimmune Retinopathy. Indian J Ophthalmol (2020) 68:1829-37. doi: 10.4103/ijo.IJO_786_20
117. Mizener JB, Kimura AE, Adamus G, Thirkill CE, Goeken JA, Kardon RH. Autoimmune Retinopathy in the Absence of Cancer. Am J Ophthalmol (1997) 123:607-18. doi: 10.1016/s0002-9394(14)71073-6

118. Detrick B, Hooks JJ. Immune Regulation in the Retina. Immunol Res (2010) 47:153-61. doi: 10.1007/s12026-009-8146-1

119. Wilhelm H, Schabet M. The Diagnosis and Treatment of Optic Neuritis. Dtsch Arztebl Int (2015) 112:616-25. doi: 10.3238/arztebl.2015.0616

120. Toosy AT, Mason DF, Miller DH. Optic Neuritis. Lancet Neurol (2014) 13:83-99. doi: 10.1016/S1474-4422(13)70259-X

121. Tadi P, Najem K, Margolin E. Amaurosis Fugax. Treasure Island (FL: StatPearls (2021).

122. Nicolaescu MM. Amaurosis Fugax. Oftalmologia (2009) 53:46-54.

123. Donaldson L, Margolin E. Vision Loss in Giant Cell Arteritis. Pract Neurol (2021). doi: 10.1136/practneurol-2021-002972

124. Maz M, Chung SA, Abril A, Langford CA, Gorelik M, Guyatt G, et al. 2021 American College of Rheumatology/Vasculitis Foundation Guideline for the Management of Giant Cell Arteritis and Takayasu Arteritis. Arthritis Care Res (Hoboken) (2021) 73:1071-87. doi: 10.1002/acr.24632

125. Baalbaki H, Jalaledin D, Lachance C, Febrer G, Rheaume M, Makhzoum JP. Characterization of Visual Manifestations and Identification of Risk Factors for Permanent Vision Loss in Patients With Giant Cell Arteritis. Clin Rheumatol (2021) 40:3207-17. doi: 10.1007/s10067-021-05643-5

126. Zborowska B, Ghabrial R, Selva D, McCluskey P. Idiopathic Orbital Inflammation With Extraorbital Extension: Case Series and Review. Eye (Lond) (2006) 20:107-13. doi: 10.1038/sj.eye.6701780

127. Dagi Glass LR, Freitag SK. Orbital Inflammation: Corticosteroids First. Surv Ophthalmol (2016) 61:670-3. doi: 10.1016/j.survophthal.2016.01.005

128. Yesiltas YS, Gunduz AK. Idiopathic Orbital Inflammation: Review of Literature and New Advances. Middle East Afr J Ophthalmol (2018) 25:71-80. doi: 10.4103/meajo.MEAJO_44_18

129. Peng L, Wu YL. Immunotherapy in the Asiatic Population: Any Differences From Caucasian Population? J Thorac Dis (2018) 10:S1482-93. doi: $10.21037 /$ jtd.2018.05.106

130. Lee J, Sun JM, Lee SH, Ahn JS, Park K, Ahn MJ. Are There Any Ethnic Differences in the Efficacy and Safety of Immune Checkpoint Inhibitors for Treatment of Lung Cancer? J Thorac Dis (2020) 12:3796-803. doi: 10.21037/ jtd.2019.08.29

131. Yang J, He X, Lv Q, Jing J, Shi H. Management of Adverse Events in Cancer Patients Treated With PD-1/PD-L1 Blockade: Focus on Asian Populations. Front Pharmacol (2019) 10:726. doi: 10.3389/fphar.2019.00726

132. Khoja L, Day D, Wei-Wu Chen T, Siu LL, Hansen AR. Tumour- and ClassSpecific Patterns of Immune-Related Adverse Events of Immune Checkpoint Inhibitors: A Systematic Review. Ann Oncol (2017) 28:2377-85. doi: 10.1093/ anNonc/mdx286

133. Wills B, Brahmer JR, Naidoo J. Treatment of Complications From Immune Checkpoint Inhibition in Patients With Lung Cancer. Curr Treat Options Oncol (2018) 19:46. doi: 10.1007/s11864-018-0562-9

134. Jacquin-Porretaz C, Nardin C, Puzenat E, Roche-Kubler B, Aubin F. And a.C. Comite De Suivi Des Effets Secondaires Des Immunotherapies). [Adverse Effects of Immune Checkpoint Inhibitors Used to Treat Melanoma and Other Cancer]. Presse Med (2017) 46:808-17. doi: 10.1016/j.lpm.2017.05.032

135. Wang XJ, Lin JZ, Yu SH, Wu SX, Luo HS, Du ZS, et al. First-Line Checkpoint Inhibitors for Wild-Type Advanced Non-Small-Cell Cancer: A Pair-Wise and Network Meta-Analysis. Immunotherapy (2019) 11:311-20. doi: 10.2217/imt-2018-0107

136. Fang T, Maberley DA, Etminan M. Ocular Adverse Events With Immune Checkpoint Inhibitors. J Curr Ophthalmol (2019) 31:319-22. doi: 10.1016/ j.joco.2019.05.002

137. Nakanishi Y, Masuda T, Yamaguchi K, Sakamoto S, Horimasu Y, Nakashima T, et al. Pre-Existing Interstitial Lung Abnormalities Are Risk Factors for Immune Checkpoint Inhibitor-Induced Interstitial Lung Disease in Non-Small Cell Lung Cancer. Respir Investig (2019) 57:451-9. doi: 10.1016/j.resinv.2019.05.002

138. El-Refai SM, Brown JD, Black EP, Talbert JC. Immune Checkpoint Inhibition and the Prevalence of Autoimmune Disorders Among Patients With Lung and Renal Cancer. Cancer Inform (2017) 16:1176935117712520. doi: 10.1177/1176935117712520

139. Johnson DB, Sullivan RJ, Ott PA, Carlino MS, Khushalani NI, Ye F, et al. Ipilimumab Therapy in Patients With Advanced Melanoma and Preexisting 
Autoimmune Disorders. JAMA Oncol (2016) 2:234-40. doi: 10.1001/ jamaoncol.2015.4368

140. Corbaux P, Maillet D, Boespflug A, Locatelli-Sanchez M, Perier-Muzet M, Duruisseaux M, et al. Older and Younger Patients Treated With Immune Checkpoint Inhibitors Have Similar Outcomes in Real-Life Setting. Eur J Cancer (2019) 121:192-201. doi: 10.1016/j.ejca.2019.08.027

141. Hurez V, Padron A, Svatek RS, Curiel TJ. Considerations for Successful Cancer Immunotherapy in Aged Hosts. Exp Gerontol (2018) 107:27-36. doi: 10.1016/j.exger.2017.10.002

142. Elias R, Giobbie-Hurder A, McCleary NJ, Ott P, Hodi FS, Rahma O. Efficacy of PD-1 \& PD-L1 Inhibitors in Older Adults: A Meta-Analysis. J Immunother Cancer (2018) 6:26. doi: 10.1186/s40425-018-0336-8

143. Chiarion Sileni V, Pigozzo J, Ascierto PA, Grimaldi AM, Maio M, Di Guardo L, et al. Efficacy and Safety of Ipilimumab in Elderly Patients With Pretreated Advanced Melanoma Treated at Italian Centres Through the Expanded Access Programme. J Exp Clin Cancer Res (2014) 33:30. doi: 10.1186/17569966-33-30

144. Prieske K, Trillsch F, Oskay-Ozcelik G, Chekerov R, Bleich C, Oliveira-Ferrer L, et al. Participation of Elderly Gynecological Cancer Patients in Clinical Trials. Arch Gynecol Obstet (2018) 298:797-804. doi: 10.1007/s00404-018-4886-2

145. Denson AC, Mahipal A. Participation of the Elderly Population in Clinical Trials: Barriers and Solutions. Cancer Control (2014) 21:209-14. doi: $10.1177 / 107327481402100305$

146. Klein SL, Morgan R. The Impact of Sex and Gender on Immunotherapy Outcomes. Biol Sex Differ (2020) 11:24. doi: 10.1186/s13293-020-00301-y

147. Conforti F, Pala L, Bagnardi V, De Pas T, Martinetti M, Viale G, et al. Cancer Immunotherapy Efficacy and Patients' Sex: A Systematic Review and MetaAnalysis. Lancet Oncol (2018) 19:737-46. doi: 10.1016/S1470-2045(18)30261-4

148. Brueckl WM, Ficker JH, Zeitler G. Clinically Relevant Prognostic and Predictive Markers for Immune-Checkpoint-Inhibitor (ICI) Therapy in Non-Small Cell Lung Cancer (NSCLC). BMC Cancer (2020) 20:1185. doi: 10.1186/s12885-020-07690-8

149. Ozdemir BC, Csajka C, Dotto GP, Wagner AD. Sex Differences in Efficacy and Toxicity of Systemic Treatments: An Undervalued Issue in the Era of Precision Oncology. J Clin Oncol (2018) 36:2680-3. doi: 10.1200/JCO.2018.78.3290

150. Reck M, Rabe KF. Precision Diagnosis and Treatment for Advanced NonSmall-Cell Lung Cancer. N Engl J Med (2017) 377:849-61. doi: 10.1056/ NEJMra1703413

151. Slawinski G, Wrona A, Dabrowska-Kugacka A, Raczak G, Lewicka E. Immune Checkpoint Inhibitors and Cardiac Toxicity in Patients Treated for Non-Small Lung Cancer: A Review. Int J Mol Sci (2020) 21:7195. doi: 10.3390/ijms21197195

152. Park RB, Jain S, Han H, Park J. Ocular Surface Disease Associated With Immune Checkpoint Inhibitor Therapy. Ocul Surf (2021) 20:115-29. doi: 10.1016/j.jtos.2021.02.004

153. Hori J, Kunishige T, Nakano Y. Immune Checkpoints Contribute Corneal Immune Privilege: Implications for Dry Eye Associated With Checkpoint Inhibitors. Int J Mol Sci (2020) 21:3962. doi: 10.3390/ijms21113962

154. Nguyen AT, Elia M, Materin MA, Sznol M, Chow J. Cyclosporine for Dry Eye Associated With Nivolumab: A Case Progressing to Corneal Perforation. Cornea (2016) 35:399-401. doi: 10.1097/ICO.0000000000000724

155. Kerty E, Elsais A, Argov Z, Evoli A, Gilhus NE. EFNS/ENS Guidelines for the Treatment of Ocular Myasthenia. Eur J Neurol (2014) 21:687-93. doi: 10.1111/ene.12359

156. Benatar M, McDermott MP, Sanders DB, Wolfe GI, Barohn RJ, Nowak RJ, et al. Efficacy of Prednisone for the Treatment of Ocular Myasthenia
(EPITOME): A Randomized, Controlled Trial. Muscle Nerve (2016) 53:363-9. doi: 10.1002/mus.24769

157. Agius MA. Treatment of Ocular Myasthenia With Corticosteroids. Yes. Arch Neurol (2000) 57:750-1. doi: 10.1001/archneur.57.5.750

158. Farmakidis C, Pasnoor M, Dimachkie MM, Barohn RJ. Treatment of Myasthenia Gravis. Neurol Clin (2018) 36:311-37. doi: 10.1016/ j.ncl.2018.01.011

159. Makarious D, Horwood K, Coward JIG. Myasthenia Gravis: An Emerging Toxicity of Immune Checkpoint Inhibitors. Eur J Cancer (2017) 82:128-36. doi: 10.1016/j.ejca.2017.05.041

160. Moorthy RS, Moorthy MS, Cunningham ETJr. Drug-Induced Uveitis. Curr Opin Ophthalmol (2018) 29:588-603. doi: 10.1097/ICU.0000000000000530

161. Fierz FC, Meier F, Chaloupka K, Boni C. Intraocular Inflammation Associated With New Therapies for Cutaneous Melanoma - Case Series and Review. Klin Monbl Augenheilkd (2016) 233:540-4. doi: 10.1055/s-0042102668

162. Pflugfelder SC, Maskin SL, Anderson B, Chodosh J, Holland EJ, De Paiva CS, et al. A Randomized, Double-Masked, Placebo-Controlled, Multicenter Comparison of Loteprednol Etabonate Ophthalmic Suspension, 0.5\%, and Placebo for Treatment of Keratoconjunctivitis Sicca in Patients With Delayed Tear Clearance. Am J Ophthalmol (2004) 138:444-57. doi: 10.1016/j.ajo.2004.04.052

163. Yoshida A, Fujihara T, Nakata K. Cyclosporin A Increases Tear Fluid Secretion via Release of Sensory Neurotransmitters and Muscarinic Pathway in Mice. Exp Eye Res (1999) 68:541-6. doi: 10.1006/exer.1998.0619

164. Davis ME, Francis JH. Cancer Therapy With Checkpoint Inhibitors: Establishing a Role for Ophthalmology. Semin Oncol Nurs (2017) 33:41524. doi: 10.1016/j.soncn.2017.08.003

165. Wladis EJ, Kambam ML. Ophthalmic Complications of Immune Checkpoint Inhibitors. Orbit (2021) 1-6. doi: 10.1080/01676830.2020.1867192

166. Liu X, Wang Z, Zhao C, Wang H, Guo X, Zhou J, et al. Clinical Diagnosis and Treatment Recommendations for Ocular Toxicities of Targeted Therapy and Immune Checkpoint Inhibitor Therapy. Thorac Cancer (2020) 11:810-8. doi: $10.1111 / 1759-7714.13327$

167. Chelala E, Hoyek S, Arej N, Kattan J, Kourie HR, Baakliny J, et al. Ocular and Orbital Side Effects of ALK Inhibitors: A Review Article. Future Oncol (2019) 15:1939-45. doi: 10.2217/fon-2018-0608

168. Alba-Linero C, Alba E. Ocular Side Effects of Checkpoint Inhibitors. Surv Ophthalmol (2021). doi: 10.1016/j.survophthal.2021.01.001

Conflict of Interest: The authors declare that the research was conducted in the absence of any commercial or financial relationships that could be construed as a potential conflict of interest.

Publisher's Note: All claims expressed in this article are solely those of the authors and do not necessarily represent those of their affiliated organizations, or those of the publisher, the editors and the reviewers. Any product that may be evaluated in this article, or claim that may be made by its manufacturer, is not guaranteed or endorsed by the publisher.

Copyright $\odot 2021$ Zhou and Wei. This is an open-access article distributed under the terms of the Creative Commons Attribution License (CC BY). The use, distribution or reproduction in other forums is permitted, provided the original author(s) and the copyright owner(s) are credited and that the original publication in this journal is cited, in accordance with accepted academic practice. No use, distribution or reproduction is permitted which does not comply with these terms. 